\author{
ANL-FRA-1998-1 \\ ARGONNE NATIONAL LABORATORY \\ 9700 South Cass Avenue \\ Argonne, IL 60439
}

\title{
EVALUATION OF FISSION PRODUCT WORTH MARGINS IN PWR SPENT NUCLEAR FUEL BURNUP CREDIT CALCULATIONS
}

by

\author{
P. J. Finck, ${ }^{*}$ R. N. Blomquist, C. G. Stenberg, and C. Jammes** \\ Reactor Analysis Division \\ *Technology Development Division \\ **Permanent Address: CEA, Cadarache, France
}

\begin{abstract}
Results reported in the FRA series of memoranda frequently are preliminary and subject to revision. Consequently they should not be quoted or referenced without the authors' permission.
\end{abstract}

Work supported by U.S. Department of Energy, Office of Civilian Radioactive Waste Management 
-ii- 


\section{DISCLAIMER}

This report was prepared as an account of work sponsored by an agency of the United States Government. Neither the United States Government nor any agency thereof, nor any of their employees, make any warranty, express or implied, or assumes any legal liability or responsibility for the accuracy, completeness, or usefulness of any information, apparatus, product, or process disclosed, or represents that its use would not infringe privately owned rights. Reference herein to any specific commercial product, process, or service by trade name, trademark, manufacturer, or otherwise does not necessarily constitute or imply its endorsement, recommendation, or favoring by the United States Government or any agency thereof. The views and opinions of authors expressed herein do not necessarily state or reflect those of the United States Government or any agency thereof. 


\section{DISCLAIMER}

Portions of this document may be illegible in electronic image products. Images are produced from the best available original document. 


\section{TABLE OF CONTENTS}

Page

ABSTRACT vii

I. INTRODUCTION AND BACKGROUND $\ldots \ldots \ldots \ldots \ldots \ldots \ldots \ldots \ldots \ldots$

1. The Experimental Database for Spent Fuel Isotopics $\ldots \ldots \ldots \ldots \ldots \ldots .3$

2. The Validation Strategy for Spent Fuel Isotopics $\ldots \ldots \ldots \ldots \ldots \ldots \ldots$

3. The Experimental Database for Actinide Worths $\ldots \ldots \ldots \ldots \ldots \ldots \ldots$. 5

4. The Validation Strategy for Actinide Worths $\ldots \ldots \ldots \ldots \ldots \ldots \ldots, 5$

5. Current Status of the Methodology $\ldots \ldots \ldots \ldots \ldots \ldots \ldots \ldots \ldots \ldots$

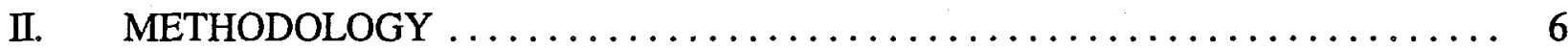

III. ANALYSIS OF THE CERES EXPERIMENTS $\ldots \ldots \ldots \ldots \ldots \ldots \ldots \ldots \ldots$

1. Methodology $\ldots \ldots \ldots \ldots \ldots \ldots \ldots \ldots \ldots \ldots \ldots \ldots \ldots \ldots, 8$

2. The CERES Experiments $\ldots \ldots \ldots \ldots \ldots \ldots \ldots \ldots \ldots \ldots \ldots \ldots$

3. The DRAGON Experimental Model $\ldots \ldots \ldots \ldots \ldots \ldots \ldots \ldots \ldots \ldots$

4. The DRAGON Nuclear Data Libraries $\ldots \ldots \ldots \ldots \ldots \ldots \ldots \ldots \ldots . \ldots \ldots$

5. Validation of DRAGON and Its 172 Group Libraries $\ldots \ldots \ldots \ldots \ldots \ldots 12$

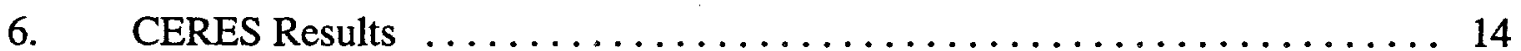

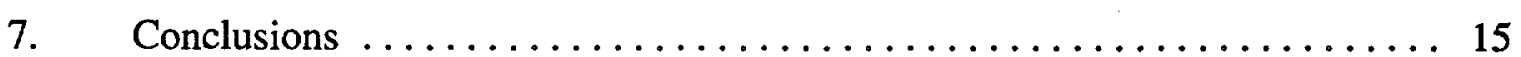

IV. COMPARISON BETWEEN ENDF/B-VI AND JEF-2.2 LIBRARIES FOR BURN-UP

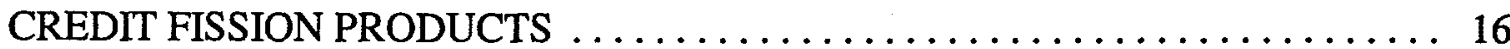

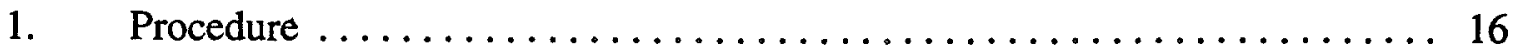

2. Results and Discussions ........................... 17

V. EVALUATION OF FISSION PRODUCT SNF CONTENT PREDICTIONS . . . . . 17 
TABLE OF CONTENTS (Contd.)

VI. DEFINITION OF MINIMAL FISSION PRODUCT WORTH $\ldots \ldots \ldots \ldots \ldots \ldots$

VII. CONCLUSIONS AND RECOMMENDATIONS $\ldots \ldots \ldots \ldots \ldots \ldots \ldots \ldots$

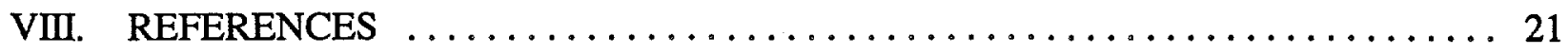

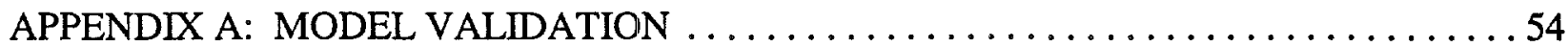




\section{LIST OF FIGURES}

Page

1. Plan View of the MINERVE Reactor (PWR Test Zone) . . . . . . . . . . 22

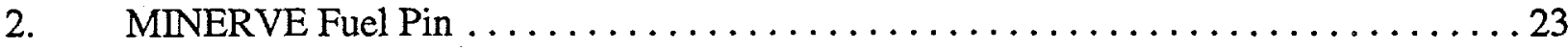

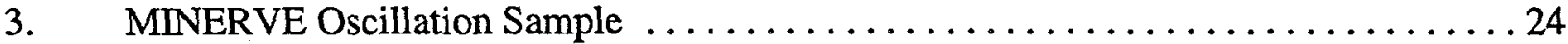

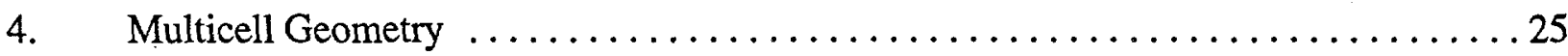

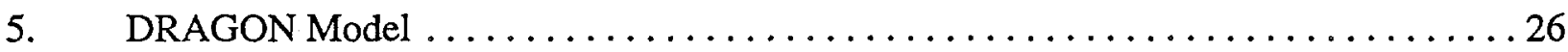

6. Comparison of ENDF/B-VI.4 and JEF-2.2 Mo-95 Capture Resonance Integrals . . . . 27

7. Comparison of ENDF/B-VI.4 and JEF-2.2 Tc-99 Capture Resonance Integrals . . . . 28

8. Comparison of ENDF/B-VI.4 and JEF-2.2 Ru-101 Capture Resonance Integrals . . . 29

9. Comparison of ENDF/B-VI.4 and JEF-2.2 Rh-103 Capture Resonance Integrals . . . 30

10. Comparison of ENDF/B-VI.4 and JEF-2.2 Ag-109 Capture Resonance Integrals . . . . 31

11. Comparison of ENDF/B-VI.4 and JEF-2.2 Cs-133 Capture Resonance Integrals . . . 32

12. Comparison of ENDF/B-VI.4 and JEF-2.2 Nd-143 Capture Resonance Integrals .... 33

13. Comparison of ENDF/B-VI.4 and JEF-2.2 Pn-147 Capture Resonance Integrals . . . 34

14. Comparison of ENDF/B-VI.4 and JEF-2.2 Pn-148m Capture Resonance Integrals . . . 35

15. Comparison of ENDF/B-VI.4 and JEF-2.2 Sm-147 Capture Resonance Integrals . . . . 36

16. Comparison of ENDF/B-VI.4 and JEF-2.2 Sm-149 Capture Resonance Integrals . . . . 37

17. Comparison of ENDF/B-VI.4 and JEF-2.2 Sm-150 Capture Resonance Integrals . . . . 38

18. Comparison of ENDF/B-VI.4 and JEF-2.2 Sm-152 Capture Resonance Integrals . . . . 39

19. Comparison of ENDF/B-VI.4 and JEF-2.2 Eu-151 Capture Resonance Integrals . . . 40

20. Comparison of ENDF/B-VI.4 and JEF-2.2 Eu-153 Capture Resonance Integrals . . . 41

21. Comparison of ENDF/B-VI.4 and JEF-2.2 Gd-155 Capture Resonance Integrals . . . 42 


\section{LIST OF TABLES}

Page

I. Absorption Rates for a $3.0 \mathrm{wt} \% \mathrm{UO}_{2}$ at $\mathrm{B}=50 \mathrm{GWd} / \mathrm{t}$, After 30 Years of Cooling ....43

II. Reactivity Worth Measurements in MINERVE R1-UO ${ }_{2}$ Calculation-Experiment

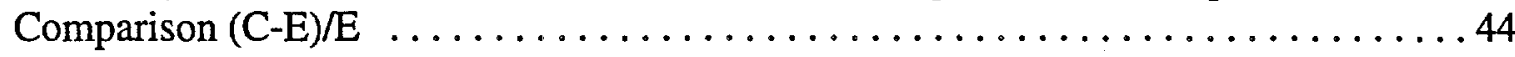

III. Number Densities for the DRAGON CERES Model $\ldots \ldots \ldots \ldots \ldots \ldots \ldots \ldots$

IV. Results of the JEF Pin Cell Benchmark $\ldots \ldots \ldots \ldots \ldots \ldots \ldots \ldots \ldots \ldots$

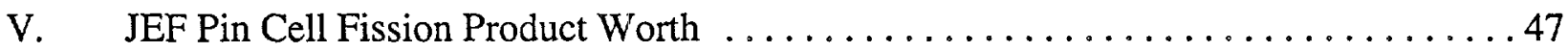

VI. CERES Analysis Results $\ldots \ldots \ldots \ldots \ldots \ldots \ldots \ldots \ldots \ldots \ldots \ldots \ldots$

VII. Summary of Available CERES Fission Product Analyses $\ldots \ldots \ldots \ldots \ldots \ldots . . \ldots 49$

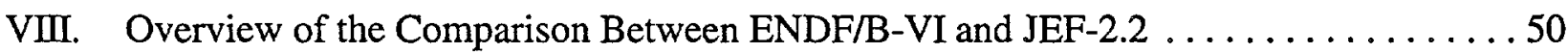

IX. Conservative Correction Factors for Fission Product Concentrations ........... 51

X. $\quad 4.5 \%$ Enriched Fuel at $50 \mathrm{GWd} / \mathrm{t}-30$ y Cooling Total FP Absorption: $17.6 \mathrm{E}-2 \ldots \ldots 52$

XI. $\quad 3.0 \%$ Enriched Fuel at $10 \mathrm{GWd} / \mathrm{t}-30$ y Cooling Total FP Absorption: $7.12 \% \ldots \ldots .53$ 


\title{
EVALUATION OF FISSION PRODUCT WORTH MARGINS IN PWR SPENT NUCLEAR FUEL BURNUP CREDIT CALCULATIONS
}

\author{
by \\ P. J. Finck (TD), R. N. Blomquist, C. G. Stenberg, and C. Jammes (CEA, Cadarache, France)
}

\begin{abstract}
Current criticality safety calculations for the transportation of irradiated LWR fuel make the very conservative assumption that the fuel is fresh. This results in a very substantial overprediction of the actual $k_{\text {eff }}$ of the transportation casks; in certain cases, this decreases the amount of spent fuel which can be loaded in a cask, and increases the cost of transporting the spent fuel to the repository.
\end{abstract}

Accounting for the change of reactivity due to fuel depletion is usually referred to as "burnup credit." The U.S. DOE is currently funding a program aimed at establishing an actinide only burnup credit methodology (in this case, the calculated reactivity takes into account the buildup or depletion of a limited number of actinides). This work is undergoing NRC review.

While this methodology is being validated on a significant experimental basis, it implicitly relies on additional margins: in particular, the absorption of neutrons by certain actinides and by all fission products is not taken into account. This provides an important additional margin and helps guarantee that the methodology is conservative provided these neglected absorptions are known with reasonable accuracy.

This report establishes the accuracy of fission product absorption rate calculations:

- the analysis of European fission product worth experiments demonstrates that fission product cross-sections available in the U.S. provide very good predictions of fission product worth;

- this is confirmed by a direct comparison of European and U.S. cross section evaluations; 
- accuracy of Spent Nuclear Fuel (SNF) fission product content predictions is established in a recent ORNL report where several SNF isotopic assays are analyzed;

- these data are then combined to establish in a conservative manner the fraction of the predicted total fission product absorption which can be guaranteed based on available experimental data. 


\section{INTRODUCTION AND BACKGROUND}

Current criticality safety analyses of spent nuclear fuel (SNF) packages are performed under the very conservative assumption that the fuel is fresh. Under optimum moderation conditions, fresh fuel $k_{\infty}$ is around 1.3 , whereas it is around 0.8 at $50 \mathrm{GWd} / \mathrm{t}$. The fresh fuel assumption leads to very limited loadings for the transportation casks and canisters: depending on canister design, the increase in the number of transported assemblies per container would be from 50 to $100 \%$ when taking the actual spent fuel composition into account in the criticality safety calculations. For the 132,000 PWR assemblies which will eventually need to be transported to a final repository, this could result in total savings of roughly one billion dollars.[1] Additional savings are likely in the construction of the repository and in the number of storage containers to be purchased.

While the decrease of $\mathrm{k}_{\infty}$ with reactivity is an intuitive notion for standard PWR fuel, large efforts have been expanded internationally to gain licensing acceptance for "burnup credit" methodologies.[2] A handful of countries have gained approval for burnup credit in either storage, transportation, or reprocessing applications.[2] The typical approach to gaining that approval has followed two phases:

- the first phase consists of developing an "actinide-only" burnup credit methodology, where it is assumed that the change in reactivity with burnup is due to a limited number of actinides (all other actinides and all fission products are ignored). Validation of this approach relies on independently validating depletion codes and neutronics codes for calculating the content and worth of these few actinides. This has been or is being implemented in several countries, where there exists a large experimental database for both actinide content and worth.

- the second phase, which is currently being considered in a few countries, consists of attempting to take into account the additional absorption due to a limited number of fission products (FPs). This approach must rely on a significantly more limited experimental database, due to the small number of available spent fuel assays with fission product measurements, and also due to the small number of FP worth measurements. 
The U.S. is currently considering an actinide only strategy for the transportation of SNF.[3] The demonstration of that strategy is undergoing successive rounds of regulatory review.

Burnup-dependent reactivity change is due to:

- decrease in the content of positive worth actinides (U-235),

- increase in the content of positive worth actinides ( $\mathrm{Pu}-239, \mathrm{Pu}-241)$,

- decrease in the content of negative worth actinides (U-238),

- increase in the content of negative worth actinides (Np-237, U-234, U-236, Pu-238, Pu240, Pu-241, Pu-242, Am-241 ...),

- increase in the content of negative worth fission products (all FPs).

Table I (from reference 4) provides a breakdown of the total absorption rate for actinides and fission products for a $3.0 \mathrm{wt} \% \mathrm{UO}_{2}$ fuel at $50 \mathrm{GWd} / \mathrm{t}$ after 30 years of cooling.

The U.S. actinides-only burnup credit methodology consists of estimating the reactivity of the fuel with a conservatively calculated content of the 10 most reactive actinides: U-234, U-235, U-238, Pu-238, Pu-239, Pu-240, Pu-241, Pu-242, and Am-241. Note that Np-237 is excluded from the list due to computational difficulties; Am-243 is not taken into account as it has significant contents only at high burnup; U-236 has been excluded as its capture cross-section is poorly known.

To make this approach acceptable to the licensing authorities, five successive technical steps are usually required:

a. Establish an experimental database of spent fuel isotopics representative of the range of conditions expected for the fuels to be transported.

b. Establish a methodology for validating any depletion code against these experimental data, and provide conservative estimates of actinide contents. 
c. Establish an experimental database of measurements of actinide worths representative of the spectra and compositions typical of spent fuel containers.

d. Establish a methodology for validating any criticality code against these experimental data, and provide conservative estimates of spent fuel worths.

e. Establish simple and conservative rules for defining the modeling parameters involved in the depletion and criticality calculations (for example, temperature distributions and soluble boron concentrations).

\section{The Experimental Database for Spent Fuel Isotopics}

The requirements for establishing an experimental database are two:

- the data should be clean and with sufficiently low uncertainties, so that later analyses are useful.

- the data should be representative of the situations to which the analysis is applied.

Reference 3 has collected a set of 54 spent fuel assays from various origins:

- several U.S. reactors (Yankee Rowe, Turkey Point, Calvert Cliffs, and Robinson),

- one Japanese reactor (Mihama),

- one Italian reactor (Trino Vercellese),

- one German reactor (Obrigheim).

The data are for various fuel types (CE, W, Siemens), various initial enrichments, two types of cladding (zircalloy and steel), and various burnups with a few points close to $50 \mathrm{GWd} / \mathrm{t}$. These data are well-documented, and generally accepted by the community as valid. As far as is known, these are also the only data easily available in the public domain. 
It is not straightforward to determine whether these data are representative of the range of situations to be analyzed (PWR assemblies in the U.S., up to maximum burnup of $50 \mathrm{GWd} / \mathrm{t}$ ). This is actually a very difficult point, as spent fuel isotopics can depend on a large number of parameters, such as assembly design, core operating parameters, initial enrichment, and assembly power history. It is therefore relatively complex to formally establish a range of applicability for a given set of experimental burnup data.

\section{The Validation Strategy for Spent Fuel Isotopics}

The validation strategy for calculating spent fuel isotopic should be applicable to any computational package, provided the same analysis technique is used consistently throughout the validation process and subsequent applications. The strategy has the following steps:

a. The isotopic inventory is calculated for the 54 benchmarks.

b. For each isotope, a linear regression analysis is performed with respect to burnup, spectral index times burnup, enrichment times burnup, and specific power times burnup. This analysis provides trends and $95 \%$ confidence interval for each of the four base parameters and each isotope. Trends which are not statistically significant are eliminated.

c. Conservative correction factors are then defined for each isotope so that there is a $95 \%$ confidence to be either above (fissile isotopes) or below (absorbers) the expected concentration.

d. These correction factors are then used throughout the criticality analyses. 


\section{The Experimental Database for Actinide Worths}

It is necessary to demonstrate that criticality code packages calculate the reactivity of the actinides used in the burnup credit strategy with adequate accuracy. Ideally, this could be done by analyzing sample worth measurements of the various actinides in the correct spectra. Unfortunately, such simple measurements are not available. The topical report devised an alternate solution, which consists of using $19 \mathrm{UO}_{2}$ critical experiments, two $\mathrm{UO}_{2}$-gadolinium critical experiments, and 36 MOX critical experiments. Representativeness of this experimental database is first demonstrated by considering the geometries of the criticals and of the expected spent nuclear fuel packages. The experimental spectra are representative of SNF conditions. In the second stage, actinide compositions of the SNF and MOX criticals are compared in a graphical manner. The report concludes from such comparisons that the concentrations of the key actinides are represented adequately in the experimental database, except for U-236.

\section{The Validation Strategy for Actinide Worths}

Here again, the proposed strategy must be applicable to any computational package. It is in principle quite similar to the strategy for spent fuel isotopics:

Step 1: The $57 \mathrm{UO}_{2}$ and MOX benchmarks are analyzed and criticality values are predicted.

Step 2: The results (C/Es) undergo statistical trending analysis with respect to several state parameters. Biases and a $95 \%$ confidence interval are defined. An administrative limit is then subtracted from the lower confidence interval. This provides the subcriticality margin that a calculation will have to demonstrate in order to ensure subcriticality with a large degree of confidence. 


\section{Current Status of the Methodology}

Two versions of the Topical Report[3] have already been submitted to the NRC, and a third revision should be submitted shortly. At each stage, NRC has requested precise information about the consequences of certain approximations made in the validation and application of the methodology. Nevertheless, while certain of these approximations might require some level of additional demonstrations, it is also clear that very sizable additional conservatism have been included in the methodology: in particular, the very large absorption due to several actinides and all fission products is ignored. For example, for the case presented in Table I ( $3.0 \mathrm{wt} \% \mathrm{UO}_{2}$ at burnup: $50 \mathrm{GWd} / \mathrm{t}$, after 30 years of cooling), $32.6 \%$ of total absorption is due to uranium isotopes initially present, $44.9 \%$ is due to other burnup credit actinides, and $22.5 \%$ is due to a few other actinides and the fission products. Thus, ignoring the fission products actually provides a very significant margin to the actinide-only burnup credit methodology. Nevertheless, the calculation of fission product worth has very little validation, and its accuracy needs to be demonstrated adequately in order to use it as an additional margin.

The objective of this report is to establish the accuracy of the fission product worth calculation: namely, based on available experimental data, what fraction of the calculated total fission product absorption can be guaranteed?

\section{METHODOLOGY}

Uncertainties or biases in the calculated fission product worth in SNF have two origins:

a. Individual fission product content of SNF can be difficult to calculate with good accuracy. This is due to weaknesses in nuclear data, and to the various approximations made in the depletion modeling with codes such as ORIGEN. The typical and most efficient way to validate these calculations is to compare them to chemical assays of 
Spent Nuclear Fuel. This has been done by ORNL in a recent report,[5] and the results of that work will be used in the present work (see Section V).

b. Individual fission product worths are expected to be calculated with relatively good accuracy, as most fission product absorption cross sections are believed to be known quite well, and as the flux spectra in a moderated SNF array are calculated with ease. Integral data for validating these calculations are unfortunately quite scarce: plant measurements of burnup swing might be too coarse to constitute a physically acceptable database, and there exist no specific measurements of fission product worths available in the public domain. We propose here to base our evaluation on recent European work: the CERES experimental program, run jointly in France and in the U.K. has produced clean experimental data to validate individual FP worths. While these data are not in the public domain, sufficient information is available to build a reasonable model of the experiments and evaluate the accuracy of U.S. nuclear data based on these measurements. This approach is detailed in Section III. Furthermore, the Europeans have validated their nuclear data (from the JEF-2.2 file) with these experiments, and have concluded that it is of sufficient quality for all practical burnup credit applications. In this report, we perform a direct comparison of European and U.S. nuclear data (from the ENDF/B-VI file) for a number of fission products, and demonstrate that the data are similar (see Section IV).

Uncertainties from these two sources (FP content, FP worth) can then be combined in a conservative manner to assess the fraction of total calculated fission product absorption which can be guaranteed based on available experimental data (see Section VI). Major contributors to total FP worth uncertainty are distinguished in Section VII, thus establishing priorities for future work. 


\section{ANALYSIS OF THE CERES EXPERIMENTS}

\section{Methodology}

The CERES experimental program[6] is still underway in France and the U.K. to determine experimental worths of SNF samples and of individual fission products in representative spectra. These very accurate experiments are probably the best approach for validating codes intended to calculate burnup credit situations. Nevertheless, the experimental data remain proprietary.

In this section, we present an alternative scheme for estimating the accuracy of the ENDF/B fission product evaluations and establishing benchmarks for validating other evaluations. This scheme relies on two observations:

a. Sufficient information has been published either in the open literature or during international technical meetings to reconstruct a detailed model of the CERES experiments,

b. While experimental results remain proprietary, some $\mathrm{C} / \mathrm{Es}$ have been published where the calculations are based on the JEF-2.2 evaluations, and are performed with either the APOLLO-2 or WIMS-7 codes. The JEF-2.2 and ENDF/B-VI evaluations are similar for the major isotopes, thus creating similar spectra. Evaluations for minor isotopes, including fission products, might be different. The CERES experimental configuration is very simple from a neutronics point of view (i.e., the flux is the fundamental mode), and it is expected that any modern lattice code will provide analytical results with good accuracy. Furthermore, the DRAGON[7] lattice code available at ANL is quite similar to APOLLO-2. Note that the published JEF results were obtained with a 172-group library and infinitely dilute FP cross sections. Thus, it is expected that the published C/Es calculated with APOLLO-2 and JEF with infinitely dilute FP cross sections can be "translated" into C/Es from ENDF/B-VI by using the relation, 


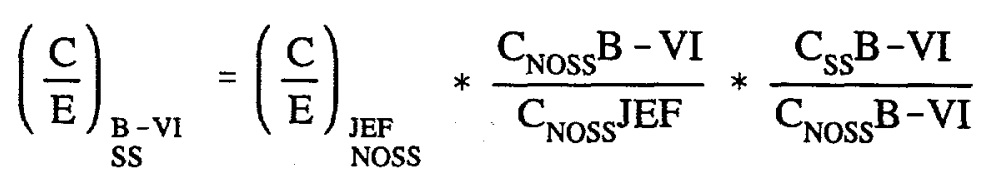

where $\mathrm{C}_{\mathrm{B}-\mathrm{VI}}$ and $\mathrm{C}_{\mathrm{JEF}}$ are calculated consistently (e.g., same group structure, same processing scheme, same lattice code, same experimental model). The SS subscript refers to calculations where FP self shielding is explicitly taken into account. The NOSS subscript refers to infinitely dilute FP cross sections.

\section{The CERES Experiments}

CERES is an international experimental program run in collaboration between CEA Cadarache (France) and AEA Technology (U.K.). Sandia national laboratory joined the program in its final U.K. phase. The program was financially supported by CEA, COGEMA, BNFL, and, in its final U.K. phase, by DOE-RW.

The program involved sample worth measurements in the DIMPLE and MINERVE reactors in the U.K. and France; the samples were irradiated fuel samples or fresh fuel samples spiked with well-determined quantities of separated fission products.

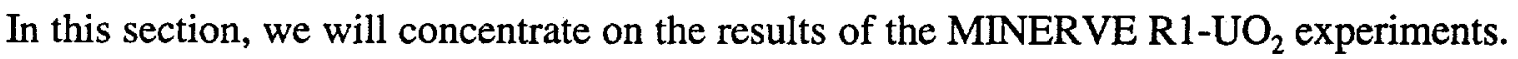
The following sources were used:

- Reference [6] provides C/Es corrected for impurities in the samples, experimental uncertainties, and masses of fission products in the samples,

- Reference [8] provides the design of the sample and sample holders,

- Reference [9] provides C/Es from the British program from JEF-2.2, ENBF/B-V, and JENDL-3.2 calculations,

- Reference [6] provides elements of the MINERVE design. 
MINERVE is a small room temperature "oscillation" reactor located at CEA-Cadarache, and is described in Fig. 1. It consists of a large annular MEU driver which surrounds a 715-mm diameter $\mathrm{Al}$ vessel containing a water moderated lattice of $\sim 800$ pins. The pitch is $1.26 \mathrm{~cm}$; the fuel is $3 \%$ enriched $\mathrm{UO}_{2}$, with density 10.2 . Fuel pins are double clad with $\mathrm{Al}_{\mathrm{x}}$; pin geometry is provided in Fig. 2. The fissile height is $\sim 500 \mathrm{~mm}$.

The central position is occupied by a sample, described in Fig. 3. The fuel in the sample is natural uranium oxide, either sintered or not. Over 15 samples, spiked with various fission products were oscillated. The measured worths were subtracted from the worths of non-spiked samples. Very extensive characterizations were obtained for all sample materials, and corrections for impurities were included in the calculational results. Published experimental uncertainties take into account uncertainties in masses, impurities, dimensions, and measurements.

The experimental setup was designed to allow for very simple modeling: the sample is essentially oscillated in and out of a fundamental mode flux shape and spectrum. Thus, very simple lattice calculations have been shown to be very accurate for analyzing these experiments.

C/Es (from Ref. [6]) are given in Table II. Calculations were performed with the APOLLO-2 2D lattice code, using standard collision probabilities for the pin cells, and linearly anisotropic interface currents (it has been shown that the results are quite insensitive to the computational options). The model is described in Fig. 4. A 172-group JEF-2.2 library was used; as is typical in some criticality calculations in Europe, this library does not contain resonance parameters for the fission products (i.e., their cross sections are infinitely dilute). Nevertheless, it should be noted that the fine 172-group structure does roughly account for the self shielding in the lowest resonance of the resonance absorbers: Tc-99 (5.6 eV); Cs-133 (5.9 eV); Ag-109 (5.2 eV). CEA Cadarache has since performed calculations with explicit FP self-shielding, but the results have not been published. 


\section{The DRAGON Experimental Model}

Several simplifications can be made to obtain a tractable model:

- The double clad can be homogenized for both the test samples and the fuel (simple Monte Carlo calculations were run and have shown that the effect of the homozenization is negligible);

- The APOLLO-2 model extends radially up to the boundary of the core; the analysis presented in this memo is aimed at calculating small sample worth ratios in a fundamental mode flux; thus, it is legitimate to reduce the size of the model to a number of pins which ensures that the sample always remains in the fundamental mode; for all calculations, leakage is modeled by making use of the fundamental mode buckling of the fuel pins.

The final DRAGON model is represented in Fig. 5: it consists of the central test pin surrounded by three rows of fuel pins. All boundary conditions are reflective. Leakage is represented by the fundamental mode buckling obtained from a pin cell calculations (using DRAGON and its ENDF/B-VI 172-group library). The same buckling was applied to all calculations.

The following DRAGON options (Ref. 7) were used:

- Self-shielding calculations were performed by the SHIBA module (this is an improved Bondarenko approach),

- Collision probability calculations were performed by the EXCEL module (exact collision probability technique).

Elements of the DRAGON validation are given in Section III.5 of this report. 
Appendix A provides some elements to validate this model; it is shown that the calculated quantities (ratio of JEF-2 worth to ENDF/B-VI worth) are not sensitive to:

- large variations of the buckling,

- $10 \%$ variation of the fuel density,

- $10 \%$ variation of the moderator density.

This behavior indicates that the results of this report should be valid, despite the uncertainties inherent to our lack of knowledge of the experimental setup.

Number densities for the various compositions in the model are given in Table III.

\section{The DRAGON Nuclear Data Libraries}

Argonne National Laboratory has generated 172 group libraries from both ENDF/B-VI and JEF-2.2 evaluations. The two libraries were created consistently, and contain all CERES fission products, both infinitely dilute and with self-shielding parameters. The group structure is identical to that of the APOLLO-2 and WIMS-7 libraries. Sections III-5 and III-6 present preliminary validation results for these libraries.

\section{Validation of DRAGON and Its 172 Group Libraries}

Our purpose here is not to fully validate DRAGON and its 172 group JEF-2.2 and ENDF/BVI libraries. Rather, it is to give preliminary indications concerning the adequacy of the library processing, and the computational options chosen in DRAGON. VIM and MCNP were used as the reference tools for this validation.

Argonne National Laboratory had generated VIM continuous energy data libraries from ENDF/B-VI and JEF-2.2 evaluations for a large number of isotopes including: 
ENDF/B-VI

U-235

U-238

O-16

$\mathrm{Zr}-90$

Zr-91

$\mathrm{Zr}-92$

$\mathrm{Zr}-93$

$\mathrm{Zr}-94$

Ag-109

Cs-133

Eu-153

Gd-155

Nd-143

Nd-145

Rh-103

Sm-147

Sm-149

Sm-152

Tc-99 $\underline{\text { JEF-2.2 }}$

U-235

U-238

O-16
Ag-109

Cs-133

Eu-153

Gd-155

Nd-143

Nd-145

Rh-103

Sm-147

Sm-149

Sm-152

Tc-99

We chose to analyze the JEF pin cell benchmark prepared by John Rowlands and extensively analyzed by the JEF community from 1993 to 1996.[10]

This benchmark has significant advantages:

- it has a very simple pin cell geometry with simplified compositions,

- it has no leakage, making it suitable for Monte Carlo analysis,

- it has been analyzed with various codes, both stochastic and deterministic, with the JEF2.2 evaluation. Significant efforts were expanded to guarantee the validity of the reference MCNP results.

Results for the benchmark are given in Table IV. They show an acceptable agreement between MCNP-JEF-2 and VIM-JEF-2: $\mathrm{k}_{\text {eff }}$ is in agreement within $250 \mathrm{pcm}$; U-235 fission and capture rates are slightly underestimated by VIM; the U-238 capture rate is slightly overestimated by VIM, the U-235 production is underestimated by VIM. These results are currently being analyzed and will be used to improve the VIM library. 
A DRAGON model of the benchmark was setup, using the SHIBA self-shielding model and the EXCEL exact collision probability module.

The JEF pin cell benchmark was modified to include in the fuel region the individual fission products studied in this work. The quantities of fission products were chosen so that acceptable VIM statistics would be produced for a limited number of histories (around 5,000,000 histories per case).

Results are given in Table V. They show an excellent agreement between the worths calculated with VIM and with DRAGON, for both B-VI and JEF-2.2 evaluations, provided the fission products are correctly self shielded. Non-negligible discrepancies exist for Sm-149; further investigations are needed to understand their origin.

6. CERES Results

Results are given in Table VI. The following conclusions can be drawn:

- Ag-109 $(\mathrm{C} / \mathrm{E}=0.929):$ the discrepancy is within two standard deviations.

- Cs-133 $(\mathrm{C} / \mathrm{E}=0.805)$ : the discrepancy is quite large; nevertheless, the experimental uncertainty was quite large, due to the small worth of the sample. Experiments have been run with higher Cs-133 content; the calculated C/E from ENDF/B-VI data with self-shielding parameters is 1.034 , which is within the experimental uncertainty.

- Eu-153 $(\mathrm{C} / \mathrm{E}=1.013):$ the agreement is excellent.

- Gd-155 $(\mathrm{C} / \mathrm{E}=0.978)$ : the discrepancy is within two standard deviations.

- Nd-143 $(\mathrm{C} / \mathrm{E}=0.935)$ : the discrepancy is somewhat high (2 standard deviations) but remains acceptable for practical cases.

- Nd-145 $(\mathrm{C} / \mathrm{E}=0.951):$ the agreement is very good.

- Rh-103 ( $\mathrm{C} / \mathrm{E}=1.117)$ : the discrepancy is somewhat high (three standard deviations) but remains acceptable for practical applications.

- Sm-147 $(\mathrm{C} / \mathrm{E}=0.833)$ : the discrepancy is quite important; nevertheless, the quoted experimental uncertainty is quite high, due to difficulties in sample characterization; additional integral data would be useful. 
- Sm-149 (C/E = 0.916) : C/Es are low for both JEF and B-VI evaluations. This result requires further analysis and might indicate a potential deficiency in the analysis scheme. Note that a non-negligible discrepancy had been observed between VIM and DRAGON for the Sm-149 spiked cell.

- Sm-152 $(\mathrm{C} / \mathrm{E}=0.928):$ the discrepancy is within two standard deviations.

- Tc-99 $(\mathrm{C} / \mathrm{E}=0.991):$ the agreement is excellent.

- Mo-95 $(\mathrm{C} / \mathrm{E}=1.014)$ : the agreement is excellent.

\section{Conclusions}

The results given in this section indicate that the ENDF/B-VI fission product evaluations appear to be sufficiently accurate for practical applications in criticality safety analyses. It is nevertheless quite clear that additional comparisons to integral experimental data are needed before formally accepting the validity of these evaluations.

While there does not seem to be any urgent need to improve the fission product evaluations, it is appropriate to establish individual evaluation weaknesses. This should be done in an international context, where projects can best pool their resources. It has been proposed to extend subgroup 17 of the Working Party of Evaluation Cooperation (WPEC): up to now, SG-17 has concentrated on the validation of fission products in the fast spectrum and included participation of the JEF and JENDL projects; the extension would concentrate on the thermal range, and we hope it will include ENDF-data. Preliminary work has already been done by the U.K.,[9] where the performances of JEF and JENDL were compared for the CERES experiments. The major conclusions of that work are that both evaluations are adequate, except for Cs-133, where JENDL performs slightly better (it should be noted that ENDF also seems to perform better than JEF), and Sm-152 and Mo-95 where JEF performs better. Table VII provides the British, French, and U.S. (from this work) results and demonstrates the overall consistency of modern nuclear data libraries. 


\section{COMPARISON BETWEEN ENDF/B-VI AND JEF-2.2 LIBRARIES FOR BURN-UP CREDIT FISSION PRODUCTS}

The objective of this section is to compare certain fission product capture cross sections from the two libraries in order to check their overall consistency.

\section{1. $\quad$ Procedure}

Pointwise cross sections were generated by the VIM library generation system.[11] In order to avoid any data processing mistake, the comparison process is automatically performed with the use of a UNIX script combined with a FORTRAN program. This package executes the following steps:

- extraction of cross section data from binary files;

- generation of a common energy mesh for both JEF and ENDF cross sections;

- computation of resonance integrals for different energy ranges.

The common energy mesh matches the most narrow-ranged resolved resonance region (RRR) of two compared cross sections. This energy mesh and the corresponding cross section are then considered as references. The cross section related to the most wide-ranged RRR is re-computed at each energy reference mesh point by using a linear-linear interpolation.

The resonance integral I is evaluated through the following expression:

$$
I=\sum_{i} \sigma_{i} \ln \frac{E_{i+1}}{E_{i}}
$$

where $\sigma_{j}$ is the cross section being considered, and $E_{i}$ and $E_{i+1}$ are two successive energy mesh points. As previously mentioned, a local resonance integral is computed for successive energy ranges. The first range starts at $0.5 \mathrm{eV}$ except for a couple of isotopes with a first resonance located beneath that limit. The last range stops at the end of the reference mesh. For each range, one also calculates an "importance" defined as: 


$$
\text { Importance }=\frac{I_{n}^{\text {ref }}}{I^{\text {ref }}} \times\left(\frac{I_{n}}{I_{n}^{\text {ref }}}-1\right) \text {, }
$$

where the superscript "ref" indicates quantities related to the reference cross section. This importance corresponds to a relative difference weighted by the ratio of the local resonance integral $I_{n}$ and the total resonance integral $I$.

\section{Results and Discussions}

The fission products of interest are listed in Table VIII. The upper limit of the RRR and the type of resonance parameters are shown for each isotope in that table. All JEF-2.2 isotopes are given with a multilevel Breit-Wigner formalism. Several ENDF/B-VI isotopes are given with a single level Breit-Wigner formalism. The upper limit of the RRR of the ENDF/B-VI library does not generally match this of the JEF-2.2 library.

For each isotope, ENDF/B-VI and JEF-2.2 cross sections are plotted. Local resonance integral and importance are also shown for successive energy ranges (see Figs. 6 to 21).

Only two out of sixteen isotopes significantly differ: technetium 99 and cesium 133 . In both cases, the observed discrepancy between resonance integrals is due to the first resonance (at $5.6 \mathrm{eV}$ for technetium 99 and at $5.9 \mathrm{eV}$ for cesium 133). The peak amplitude of that resonance is not the same for both libraries. For technetium-99, ENDF/B-VI cross section is above the JEF-2.2 one. For the cesium 133, the ENDF/B-VI cross section is below the JEF-2.2 one.

Although a few small differences generally appear in the upper part of the RRR, cross sections of both libraries are mainly consistent. This provides further confidence in the adequacy of transposing the JEF-2.2 validation to ENDF/B-VI.

\section{EVALUATION OF FISSION PRODUCT SNF CONTENT PREDICTIONS}

This section summarizes results from Ref. 5: "An Extension of the Validation of SCALE (SAS2H) Isotopic Predictions for PWR Spent Fuel," by DeHart and Hermann. To our knowledge, this constitutes the most recent and most complete U.S. work aimed at validating a depletion analysis tool with respect to experimental data for actinides and fission products. 
The report analyzes open literature experimental data from commercial PWR spent fuel. Representative SCALE models of the irradiated sample locations were built, and accurate time power histories were used to obtain the end of life isotopics. Two nuclear data libraries were used: a 27 group library derived from ENDF/B-IV and a 44 group library derived from ENDF/B-V (three isotopes, O-16, Eu-154, and Eu-155 were derived from more recent ENDF/B-VI evaluations). The resulting E/Cs (measured over calculated value) were analyzed in a statistical manner; conservative (for criticality safety purposes) correction factors were derived for each isotope so that the product $\mathrm{C}_{\mathrm{i}}{ }^{*} \mathrm{f}_{\mathrm{i}}$ (where $\mathrm{C}_{\mathrm{i}}$ is the calculated concentration for isotope $\mathrm{i}$, and $\mathrm{f}_{\mathrm{i}}$ is the relevant correction factor) maximizes reactivity in a criticality safety calculation. For absorbers, $C_{i}{ }^{*} f_{i}$ is the minimal quantity of that isotope which can be guaranteed to exist in the actual spent nuclear fuel. It should be noted that $C_{i}$ and $f_{i}$ need to be estimated consistently: in particular, they should be obtained for the same library.

Table IX gives $f_{i}$ for a series of fission products of interest for both libraries. It should be noted that for two isotopes (Sm-149; Gd-155) the statistical treatment yields negative f values; in these cases $\mathrm{f}$ is taken to be the lowest of all available C/Es. For three isotopes (Mo-95, Ag-109, and $\mathrm{Rh}-103$ ) no experimental information was provided: the value of $f$ was inferred from the authors' personal experience and unpublished non-U.S. results.

Several observations can be made:

- the experimental basis is sometimes very limited (in certain cases, there exist only three measurements, all from the same origin);

- except for Gd-153, there is no significant improvement between the two libraries. This is probably due to the sparse experimental database;

- the experimental database does not seem to be consistent: there seem to exist a few outlying measurements which should probably be eliminated. 


\section{DEFINITION OF MINIMAL FISSION PRODUCT WORTH}

It is our objective here to assess the worth of fission products in SNF which can be guaranteed from available experimental data. A conservative approach can be defined as follows:

$$
\text { FP worth }=\sum_{i=1}^{N} \quad C_{i} f_{i} \times \text { worth(i) }
$$

where: $\quad \mathrm{i}=1 \ldots \mathrm{N}$ are the fission products for which experimental data are available

- $\mathrm{C}_{\mathrm{i}}$ is the calculated concentration for isotope $\mathrm{i}$

- $\mathrm{f}_{\mathrm{i}}$ is the isotopic correction factor (obtained with the same library as is used for $\mathrm{C}_{\mathrm{i}}$ )

- worth( $i$ ) is the minimal worth of isotope $i$, defined conservatively as the calculated worth multiplied by the smallest E/C from Table VIII (given as the gi factor). Note that worth(i) is library-independent.

This methodology is illustrated for two types of fuel:

- $\quad 4.5 \mathrm{wt} \%$ enriched fuel at $50 \mathrm{GWd} / \mathrm{t}$ after 30 years of cooling. The calculated FP absorptions are from Ref. [4], where the 27 group library was used. Results are given in Table X: the total calculated FP absorption is $17.6 \%$; experimental data are available for $11.6 \% ; 8.2 \%$ can be guaranteed from a conservative analysis.

- $\quad 3.0 \mathrm{wt} \%$ enriched fuel at $10 \mathrm{GWd} / \mathrm{t}$ after 30 years of cooling. The calculated FP absorptions are from Ref. [4], where the 27 group SCALE library was used. Results are given in Table XI: the total calculated FP absorption is $7.12 \%$, experimental data are available for $3.3 \% ; 2.3 \%$ can be guaranteed from a conservative analysis.

The following trends can be observed in these two cases:

- the largest loss of information on the total FP worth is due to the lack of experimental data for a large number of FPs which have small individual contributions. 
- the next largest loss of information is due to the lack of sufficient experimental data for SNF isotopic content, which forces very conservative margins on the calculations.

- the uncertainties of the individual FP capture cross sections contribute little to the overall uncertainty.

\section{CONCLUSIONS AND RECOMMENDATIONS}

Two major conclusions can be drawn from this work:

a. Based on available experimental evidence, the cross sections evaluations for the Fission Products of interest (Sm: 147, 149, 152; Nd: 143, 145; Gd-155; Rh-103; Cs133, Tc-99; Mo-95; Eu-153; Ag-109) are of high quality and do not require reevaluation for burnup credit applications. Nevertheless, the integral experimental data used in this work has only been published partially, and our demonstration, while technically correct, do not meet Quality Assurance requirements for Burnup Credit applications. Consequently, it is important for the U.S. program to acquire high quality independent experimental data to be used for validating its approach. Such experiments are under development at LANL, using the samples from the CERES program.

b. For high burnup fuel, it appears that slightly under half of the total calculated FP absorption can be guaranteed from experimental data. The major contribution to the unknown fraction is from fission products for which there are no experimental data (for worth or content). Considering the cost associated to worth measurements for any new isotope, and the small individual contribution of isotopes not already measured, it does not appear to be cost effective to request inclusion of additional isotopes in the program. Nevertheless, the next major contribution to the unknown fraction of total FP absorption is the poor statistics on fuel FP content predictions. This in turn is related to the very limited number of fuel chemical assays available. Additional assays could significantly help reduce the uncertainty on FP worth in SNF. 


\section{REFERENCES}

1. W. H. Lake, "Cost Saving Potential for Transport and Storage of Spent Nuclear Fuel Available from Burnup Credit," Trans. Am. Nucl. Soc., 76, June 1997.

2. Implementation of Burnup Credit in Spent Fuel Management Systems, IAEA-TEC DOC1013, April 1998.

3. Topical Report on Actinide-Only Burnup Credit for PWR Spent Nuclear Fuel Packages, DOE/RW-0472, Rev. 1, May 1997.

4. Sensitivity and Parametric Evaluations of Significant Aspects of Burnup Credit for PWR Spent Fuel Packages, ORNL/TM-12973.

5. An Extension of the Validation of SCALE (SAS2H) Isotopic Predictions for PWR Spent Fuel, ORNLTM-13317.

6. A. Santamarina et al., "The French Experimental Programme on Burnup Credit," Procs. Topical Mtg. On Criticality Safety Challenges in the Next Decade, Chelan, WA, Sept. 1997.

7. G. Marleau et al., "A User's Guide for DRAGON," Ecole Polytechnique de Montréal, December 1997.

8. A Santamarina et al., presentations at meeting of the Working party on Nuclear Criticality Safety $(1997,1998)$.

9. N. T. Gulliford, presentation to the Nuclear Criticality Technology Safety Project, Albuquerque, NM, May 1998.

10. J. Rowlands et al., "LWR Pin Cell Benchmark Intercomparisons," PHYSOR '97, Mito, Japan, September 1997.

11. R. E. Prael, "Cross Section Preparation for the Continuous-Energy Monte Carlo Code VIM," Proc. Conf. on Nuclear Cross Sections and Technology, NBS SP 425, p. 447 (March 3-7, 1975). 


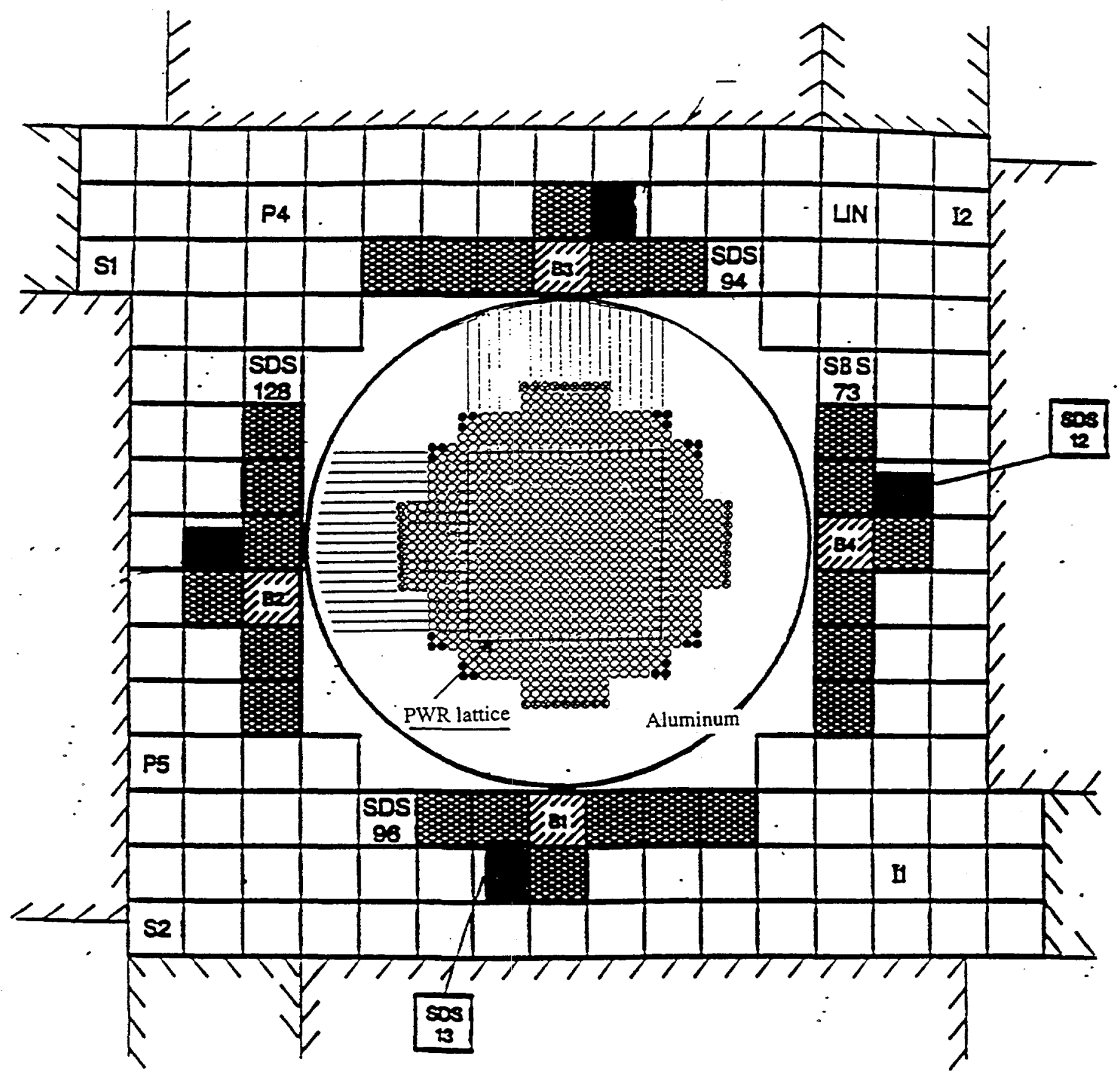

Fig. 1. Plan View of the MINERVE Reactor (PWR Test Zone) 


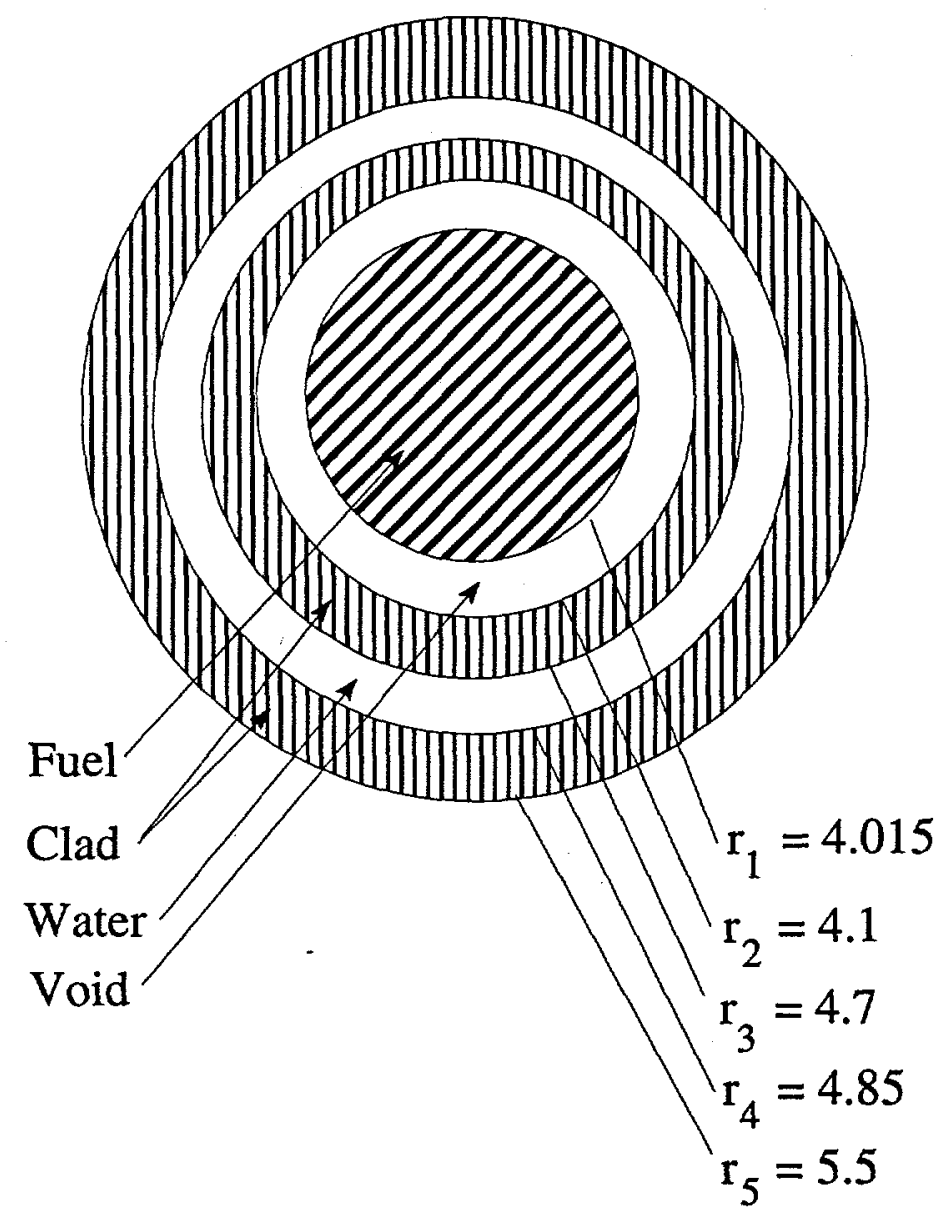

Dimensions in $\mathrm{mm}$

Fig. 2. MINERVE Fuel Pin 


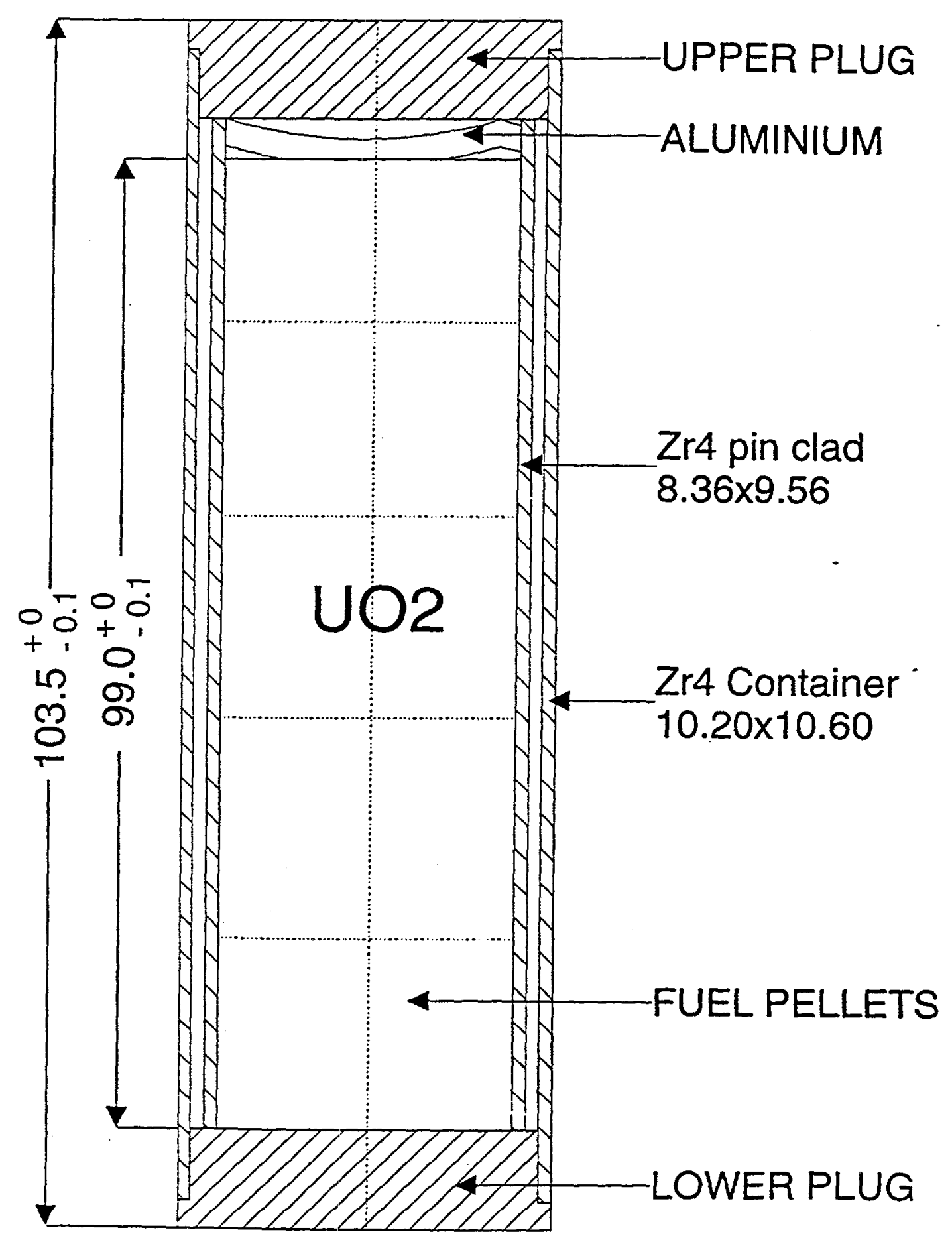

Fig. 3. MINERVE Oscillation Sample 
1 : Oscillation cell

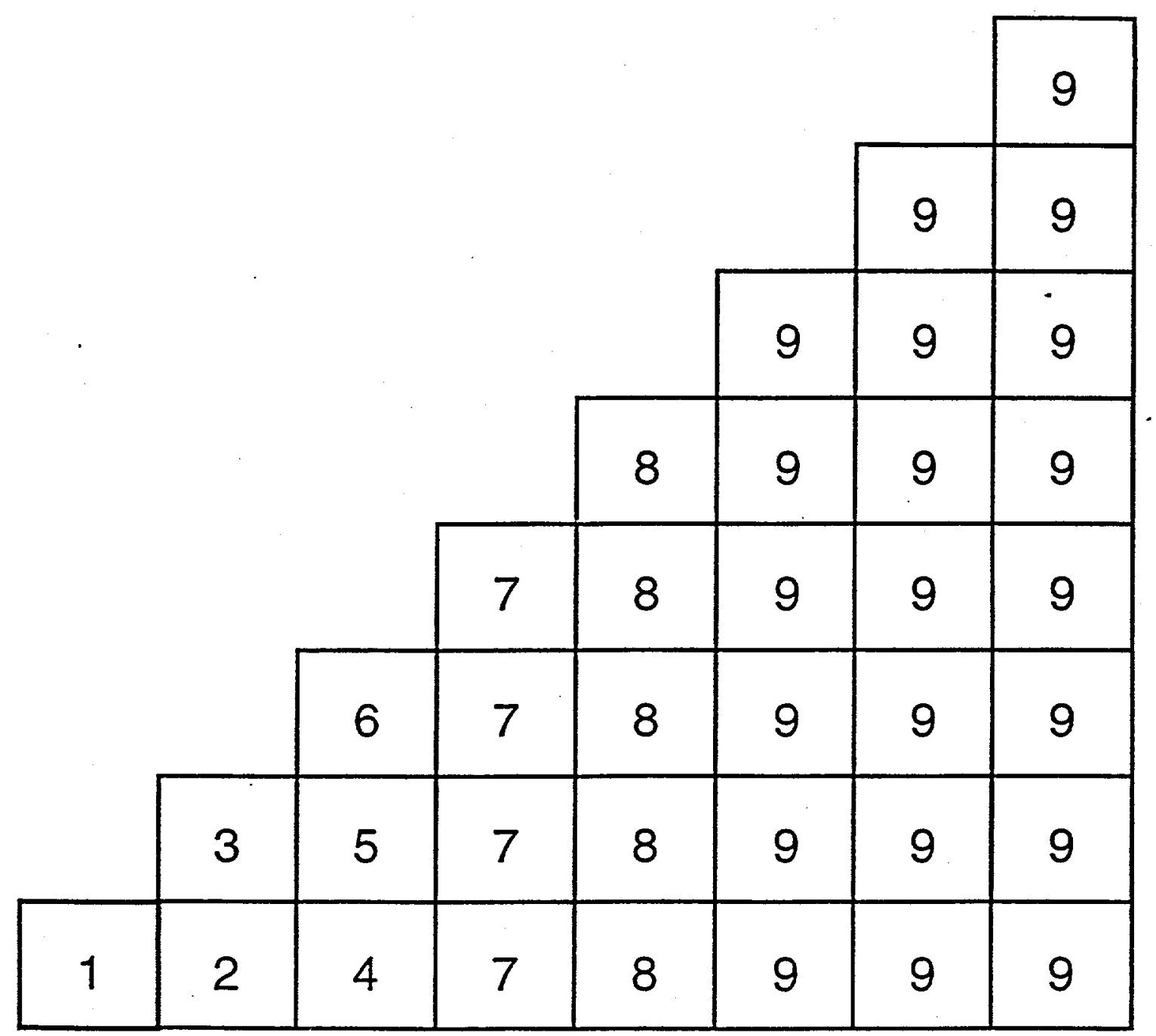

- $\mathrm{P}_{\mathrm{IJ}}^{2 \mathrm{D}}$ calculations

- $\Delta \rho=\frac{\left\langle\phi^{+}, \Delta H \tilde{\phi}\right\rangle}{\left\langle\phi^{+}, P \tilde{\phi}\right\rangle}$ Exact Perturbation Formula

Fig. 4. Multicell Geometry 

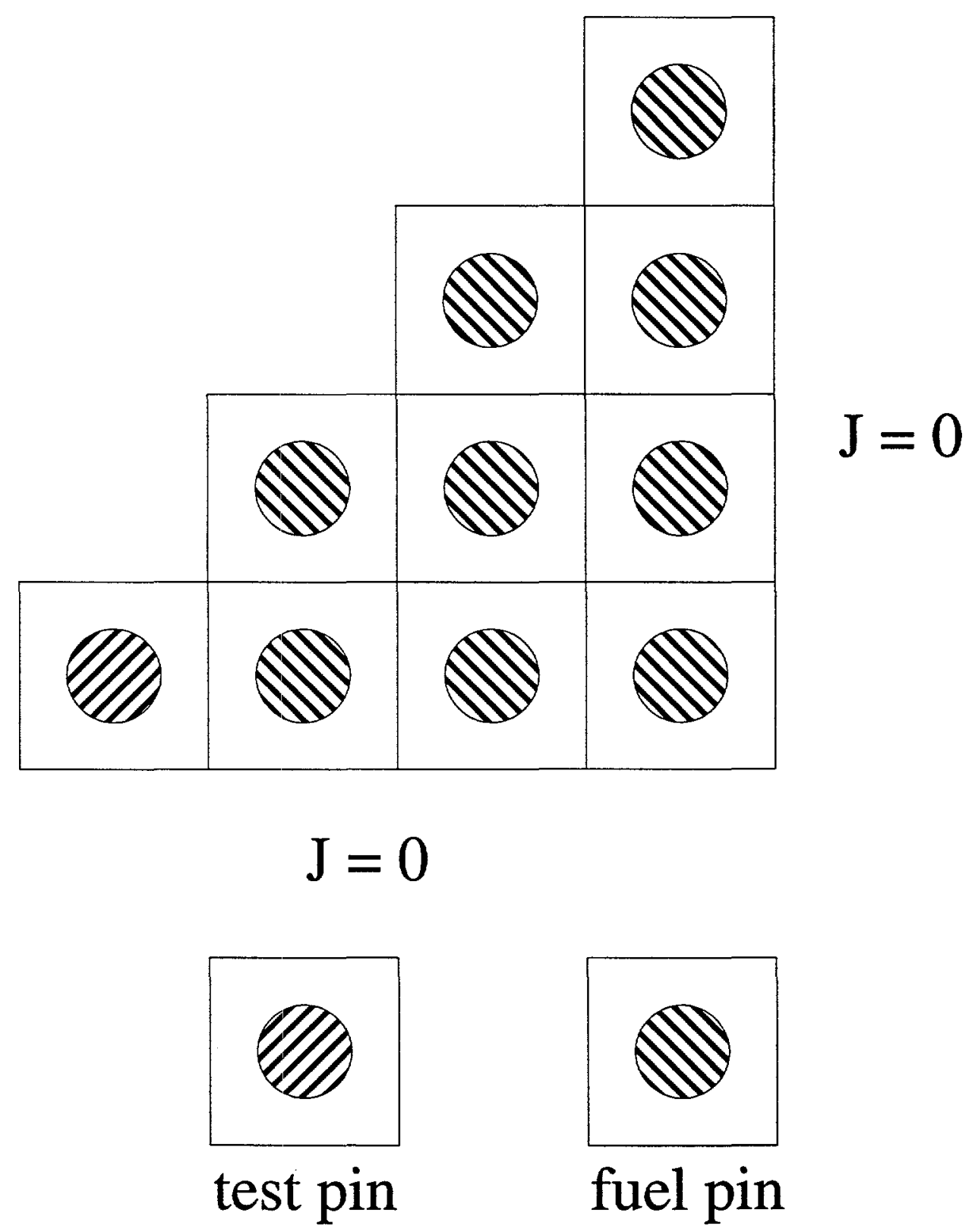

Fig. 5. DRAGON Model 


\section{Molybdenum 95}

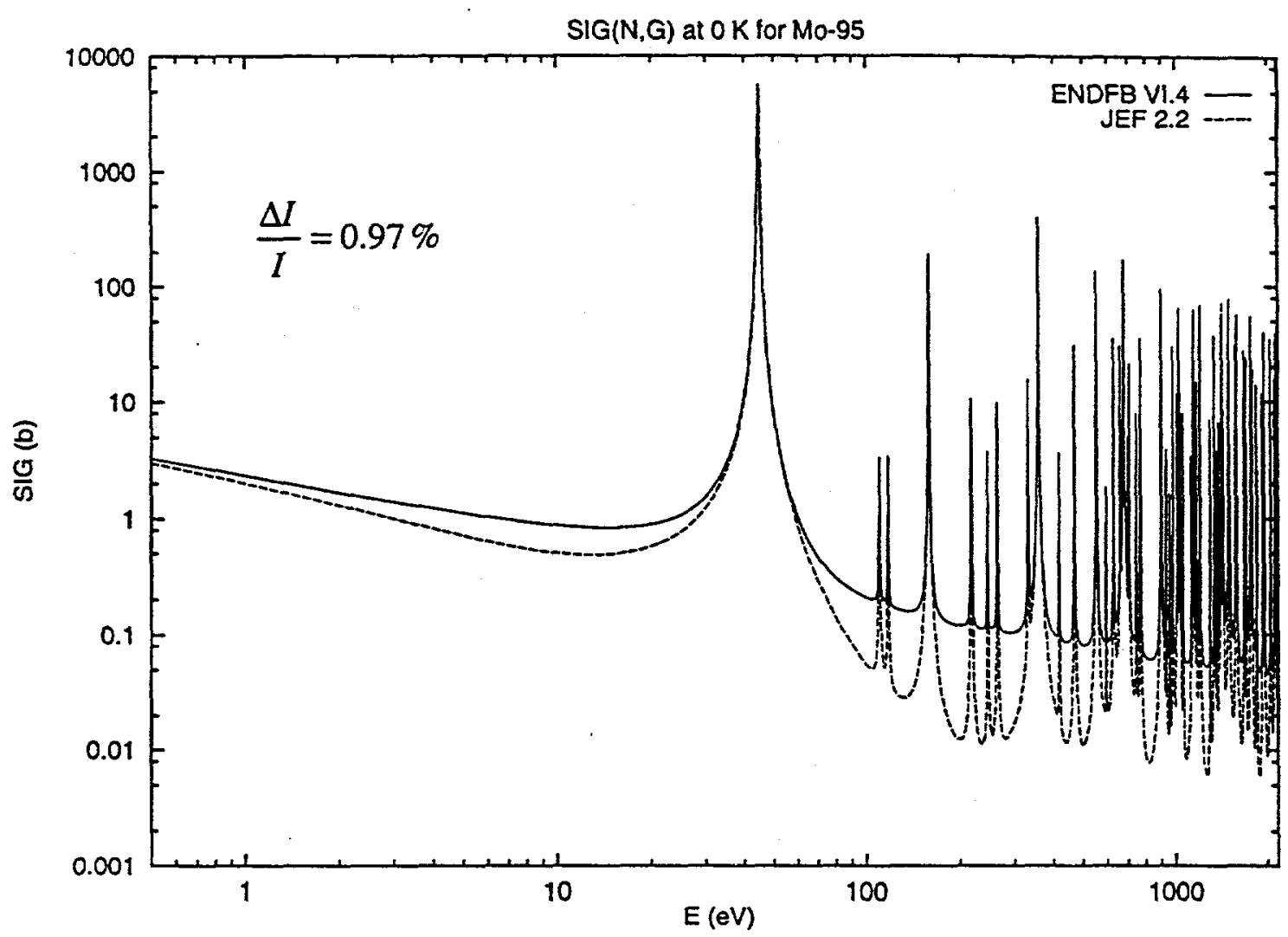

\begin{tabular}{|c|c|c|c|c|}
\hline \multicolumn{2}{|c|}{ Energy range (eV) } & I(b)-JEF & I(b)-ENDF & $\begin{array}{c}\text { Importance } \\
(\%)\end{array}$ \\
\cline { 1 - 4 } $\mathbf{E}_{\min }$ & $\mathbf{E}_{\max }$ & $\mathbf{\%})$ & 0.15 \\
\hline 0.5 & 0.75 & 1.19 & 1.33 & 0.10 \\
\hline 0.75 & 1 & 0.60 & 0.69 & 0.36 \\
\hline 1 & 2.5 & 1.28 & 1.59 & 0.38 \\
\hline 2.5 & 5 & 0.62 & 0.91 & 0.27 \\
\hline 5 & 7.5 & 0.28 & 0.46 & 0.17 \\
\hline 7.5 & 10 & 0.15 & 0.25 & 0.43 \\
\hline 10 & 25 & 0.48 & 0.77 & -0.61 \\
\hline 25 & 50 & 95.81 & 95.15 & 0.07 \\
\hline 50 & 75 & 0.62 & 0.69 & 0.11 \\
\hline 75 & 100 & 0.02 & 0.07 & 0.07 \\
\hline 100 & 500 & 3.30 & 3.38 & 0.04 \\
\hline 500 & 1000 & 1.71 & 1.75 & 0.07 \\
\hline 1000 & 2168.4 & 1.48 & 1.56 & \\
\hline
\end{tabular}

Fig. 6. Comparison of ENDF/B-VI.4 and JEF-2.2 Mo-95 Capture Resonance Integrals 


\section{Technetium 99}

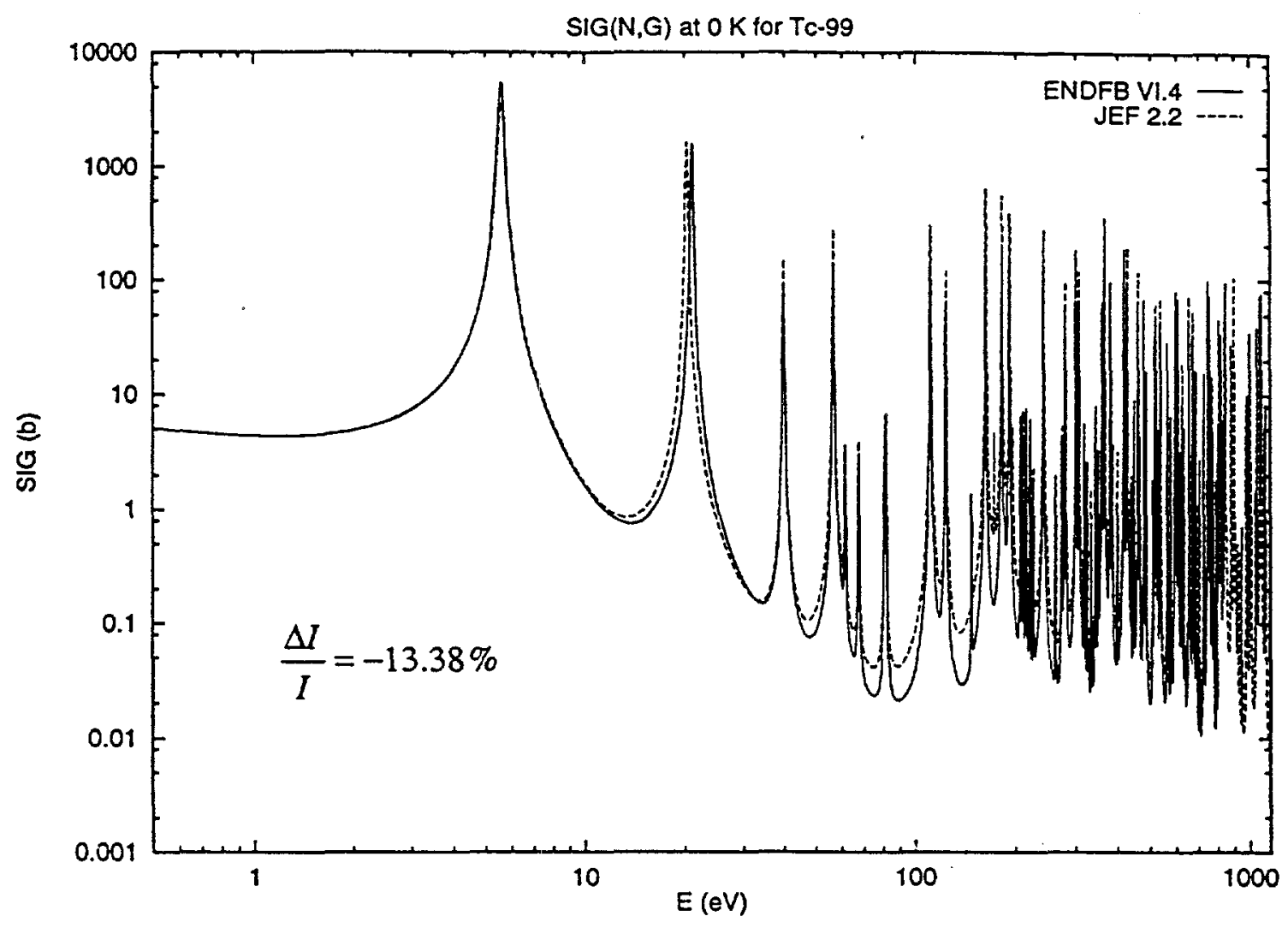

\begin{tabular}{|c|c|c|c|c|}
\hline \multicolumn{2}{|c|}{ Energy range (eV) } & \multirow{2}{*}{ I(b)-JEF } & \multirow{2}{*}{ I(b)-ENDF } & \multirow{2}{*}{$\begin{array}{c}\text { Importance } \\
(\%)\end{array}$} \\
\hline $\mathrm{E}_{\min }$ & $E_{\max }$ & & & \\
\hline 0.5 & 0.75 & 1.5908 & 1.5861 & 0.00 \\
\hline 0.75 & 1 & 1.503 & 1.5057 & 0.00 \\
\hline 1 & 2.5 & 3.2886 & 3.3193 & 0.01 \\
\hline 2.5 & 5 & 12.506 & 12.456 & -0.02 \\
\hline 5 & 7.5 & 271.12 & 212.57 & -15.75 \\
\hline 7.5 & 10 & 0.92952 & 0.97629 & 0.02 \\
\hline 10 & 25 & 33.157 & 31.923 & -0.41 \\
\hline 25 & 50 & 1.2772 & 2.0005 & 0.39 \\
\hline 50 & 75 & 1.5208 & 2.9303 & 0.93 \\
\hline$\overline{75}$ & 100 & 0.070371 & 0.10758 & 0.02 \\
\hline 100 & 500 & 8.2057 & 20.049 & 9.93 \\
\hline 500 & 800 & 1.2858 & 2.0291 & 0.40 \\
\hline
\end{tabular}

Fig. 7. Comparison of ENDF/B-VI.4 and JEF-2.2 Tc-99 Capture Resonance Integrals 


\section{Ruthenium 101}

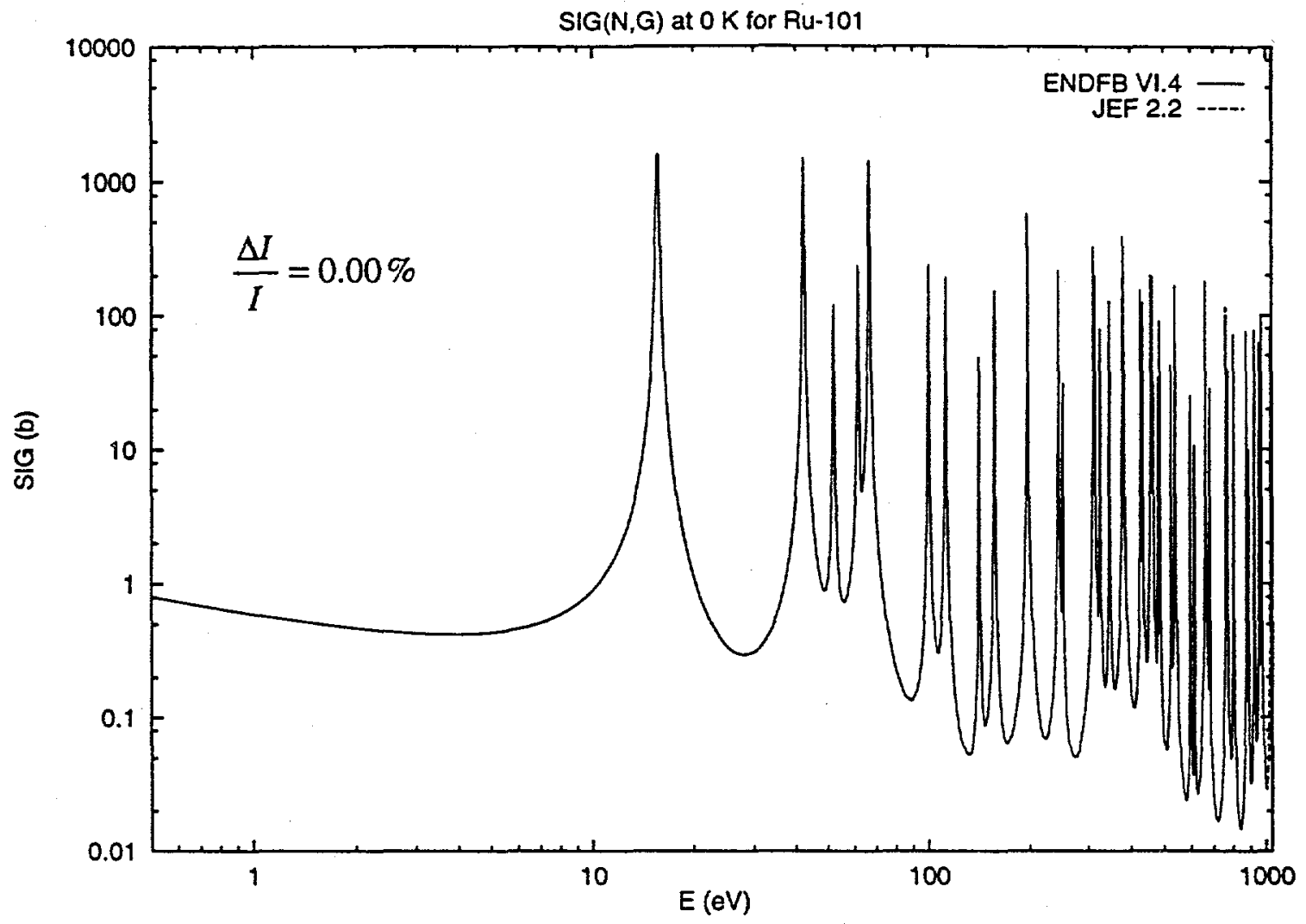

\begin{tabular}{|c|c|c|c|c|}
\hline \multicolumn{2}{|c|}{ Energy range (eV) } & \multirow{2}{*}{ I(b)-JEF } & \multirow{2}{*}{ I(b)-ENDF } & \multirow{2}{*}{$\begin{array}{c}\text { Importance } \\
(\%)\end{array}$} \\
\hline $\mathbf{E}_{\min }$ & $\mathrm{E}_{\max }$ & & & \\
\hline 0.5 & 0.75 & 0.35756 & 0.35757 & 0.00 \\
\hline 0.75 & 1 & 0.19918 & 0.19919 & 0.00 \\
\hline 1 & 2.5 & 0.40842 & 0.40845 & 0.00 \\
\hline 2.5 & 5 & 0.246 & 0.246 & 0.00 \\
\hline 5 & 7.5 & 0.17598 & 0.17599 & 0.00 \\
\hline 7.5 & 10 & 0.23627 & 0.23627 & 0.00 \\
\hline 10 & 25 & 44.281 & 44.281 & 0.00 \\
\hline 25 & 50 & 19.097 & 19.097 & 0.00 \\
\hline 50 & 75 & 18.26 & 18.26 & 0.00 \\
\hline 75 & 100 & 0.54128 & 0.54133 & 0.00 \\
\hline 100 & 500 & 15.931 & 15.938 & 0.01 \\
\hline 500 & 1000 & 2.4874 & 2.4814 & -0.01 \\
\hline
\end{tabular}

Fig. 8. Comparison of ENDF/B-VI.4 and JEF-2.2 Ru-101 Capture Resonance Integrals 


\section{Rhodium 103}

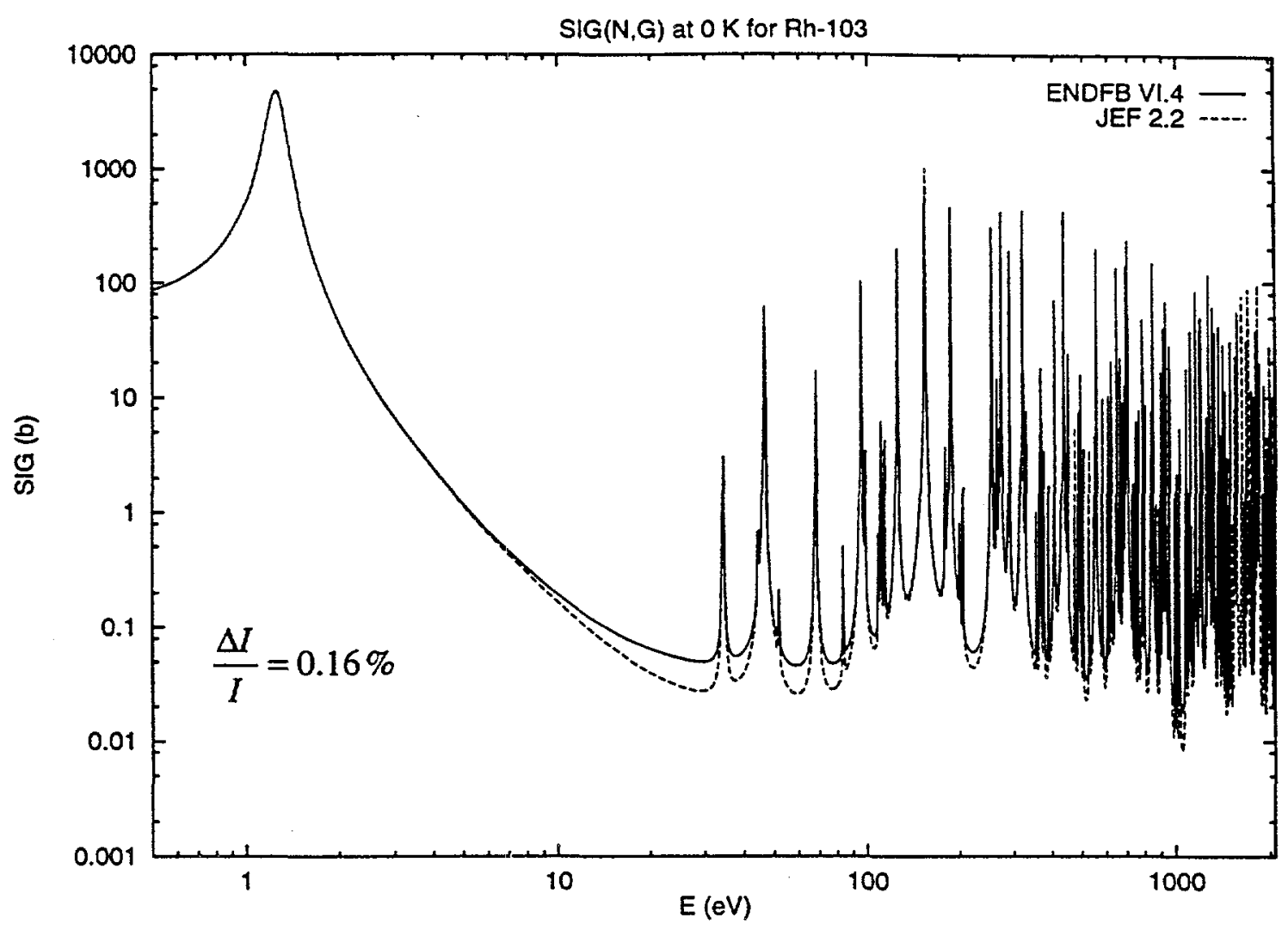

\begin{tabular}{|c|c|c|c|c|}
\hline \multicolumn{2}{|c|}{ Energy range (eV) } & \multirow{2}{*}{ I(b)-JEF } & \multirow{2}{*}{ I(b)-ENDF } & \multirow{2}{*}{$\begin{array}{c}\text { Importance } \\
(\%)\end{array}$} \\
\hline $\mathrm{E}_{\min }$ & $\mathbf{E}_{\max }$ & & & \\
\hline 0.5 & 0.75 & 46.715 & 46.695 & 0.00 \\
\hline 0.75 & 1 & 78.782 & 78.769 & 0.00 \\
\hline 1 & 2.5 & 861.51 & 861.36 & -0.01 \\
\hline 2.5 & 5 & 3.4292 & 3.4057 & 0.00 \\
\hline 5 & 7.5 & 0.28571 & 0.27102 & 0.00 \\
\hline 7.5 & 10 & 0.058935 & 0.051278 & 0.00 \\
\hline 10 & 25 & 0.080227 & 0.056589 & 0.00 \\
\hline 25 & 50 & 0.80213 & 0.79383 & 0.00 \\
\hline 50 & 75 & 0.18383 & 0.14813 & 0.00 \\
\hline 75 & 100 & 0.79573 & 0.81186 & 0.00 \\
\hline 100 & 500 & 15.9 & 17.85 & 0.22 \\
\hline 500 & 1000 & 3.0873 & 3.0914 & 0.00 \\
\hline 1000 & 1500 & 1.1777 & 1.1408 & 0.00 \\
\hline
\end{tabular}

Fig. 9. Comparison of ENDF/B-VI.4 and JEF-2.2 Rh-103 Capture Resonance Integrals 


\section{Silver 109}

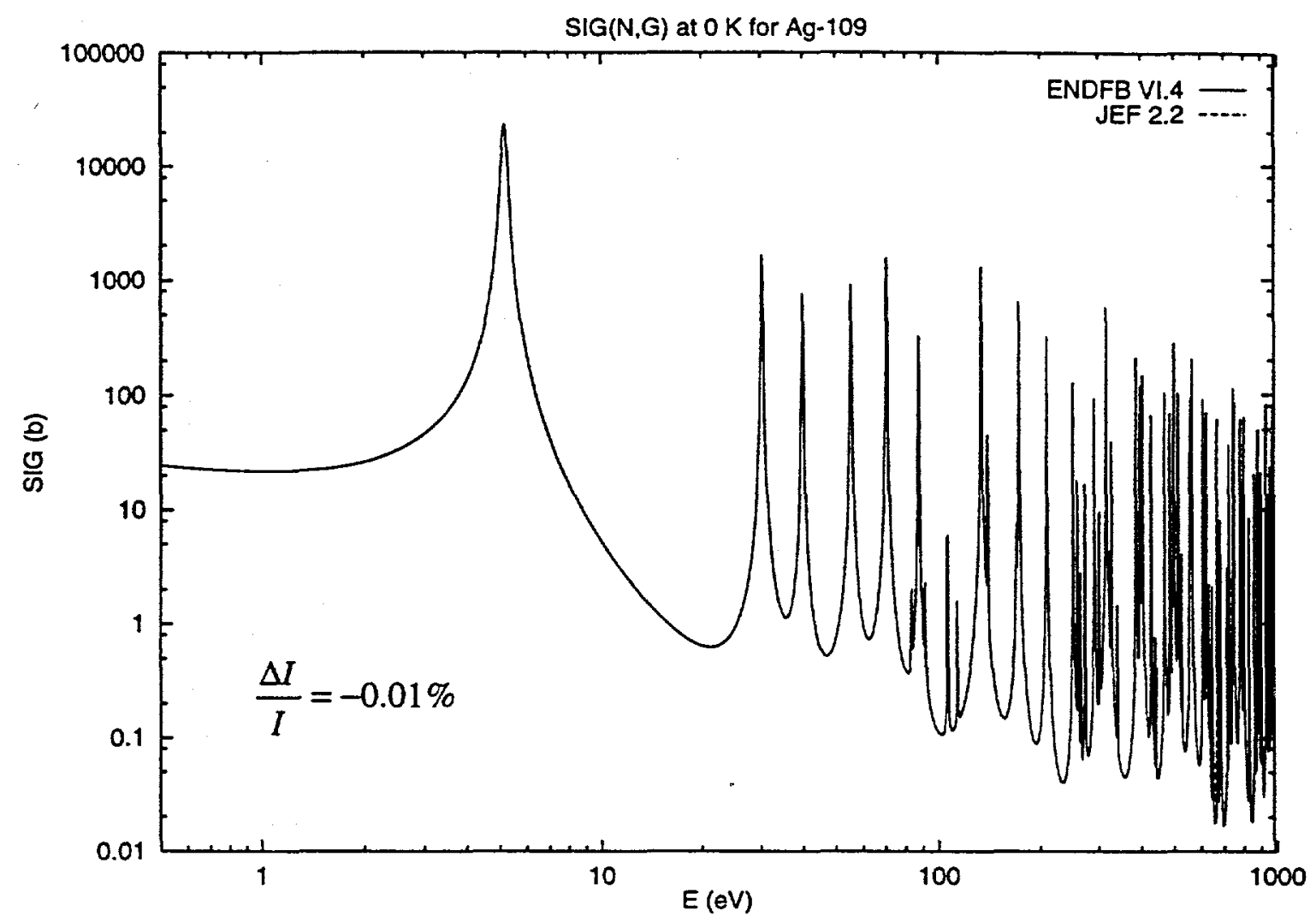

\begin{tabular}{|c|c|c|c|c|}
\hline \multicolumn{2}{|c|}{ Energy range (eV) } & I(b)-JEF & I(b)-ENDF & $\begin{array}{c}\text { Importance } \\
(\%)\end{array}$ \\
\cline { 1 - 2 } $\mathbf{E}_{\min }$ & $\mathbf{E}_{\max }$ & $(\mathbf{\%})$ & 0.00 \\
\hline 0.5 & 0.75 & 10.598 & 10.599 & 0.00 \\
\hline 0.75 & 1 & 7.5498 & 7.5504 & 0.00 \\
\hline 1 & 2.5 & 19.148 & 19.149 & 0.00 \\
\hline 2.5 & 5 & 203.47 & 203.47 & 0.00 \\
\hline 5 & 7.5 & 1146.7 & 1146.7 & 0.00 \\
\hline 7.5 & 10 & 3.1023 & 3.1025 & 0.00 \\
\hline 10 & 25 & 1.0608 & 1.0611 & 0.00 \\
\hline 25 & 50 & 32.813 & 32.814 & 0.00 \\
\hline 50 & 75 & 23.138 & 23.138 & 0.00 \\
\hline 75 & 100 & 2.4639 & 2.4642 & 0.00 \\
\hline 100 & 500 & 19.563 & 19.564 & -0.01 \\
\hline 500 & 983.17 & 3.9872 & 3.8598 & \\
\hline
\end{tabular}

Fig. 10. Comparison of ENDF/B-VI.4 and JEF-2.2 Ag-109 Capture Resonance Integrals 


\section{Cesium 133}

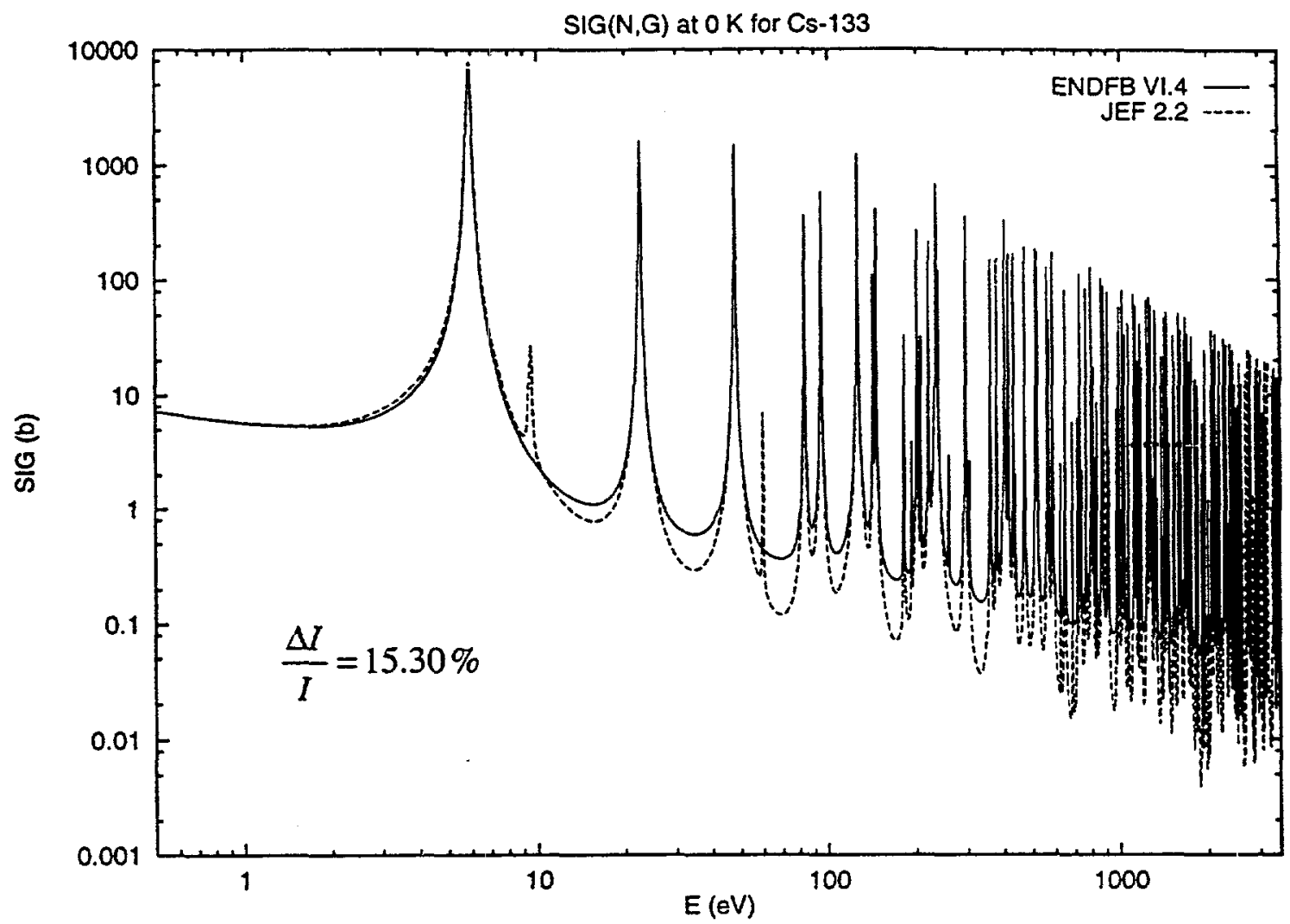

\begin{tabular}{|c|c|c|c|c|}
\hline \multicolumn{2}{|c|}{ Energy range $(\mathrm{eV})$} & \multirow{2}{*}{ I(b)-JEF } & \multirow{2}{*}{ I(b)-ENDF } & \multirow{2}{*}{$\begin{array}{c}\text { Importance } \\
(\%)\end{array}$} \\
\hline $\mathbf{E}_{\text {min }}$ & $\mathrm{E}_{\max }$ & & & \\
\hline 0.5 & 0.75 & 3.3157 & 3.3128 & 0.00 \\
\hline 0.75 & 1 & 1.943 & 1.9643 & 0.00 \\
\hline 1 & 2.5 & 3.8083 & 3.9816 & 0.04 \\
\hline 2.5 & 5 & 7.5783 & 8.8149 & 0.33 \\
\hline 5 & 7.5 & 282.29 & 338.93 & 15.64 \\
\hline 7.5 & 10 & 1.1851 & 2.4852 & 0.63 \\
\hline 10 & 25 & 26.214 & 25.595 & -0.14 \\
\hline 25 & 50 & 15.71 & 15.022 & -0.15 \\
\hline 50 & 75 & 0.27508 & 0.37812 & 0.03 \\
\hline 75 & 100 & 6.5477 & 6.1986 & -0.08 \\
\hline 100 & 500 & 22.277 & 22.293 & 0.00 \\
\hline 500 & 1000 & 3.4971 & 3.5464 & 0.01 \\
\hline 1000 & 2500 & 2.4267 & 2.2514 & -0.04 \\
\hline
\end{tabular}

Fig. 11. Comparison of ENDF/B-VI.4 and JEF-2.2 Cs-133 Capture Resonance Integrals 


\section{Neodymium 143}

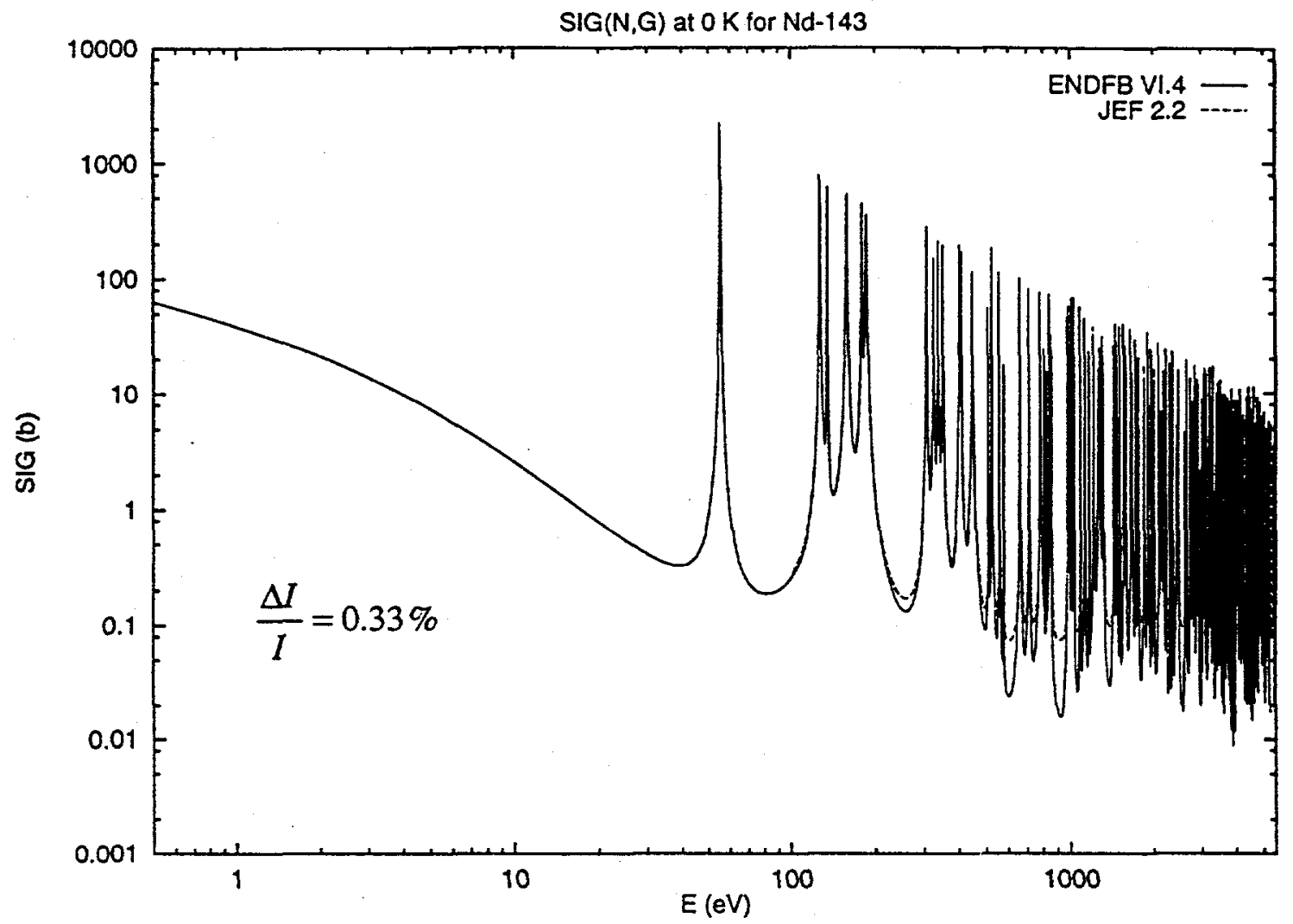

\begin{tabular}{|c|c|c|c|c|}
\hline \multicolumn{2}{|c|}{ Energy range (eV) } & I(b)-JEF & I(b)-ENDF & $\begin{array}{c}\text { Importance } \\
(\boldsymbol{\%})\end{array}$ \\
\cline { 1 - 2 } $\mathbf{E}_{\min }$ & $\mathbf{E}_{\max }$ & & 24.039 & 0.04 \\
\hline 0.5 & 0.75 & 23.993 & 13.417 & 0.00 \\
\hline 0.75 & 1 & 13.416 & 19.49 & 0.00 \\
\hline 1 & 2.5 & 19.488 & 7.4964 & 0.00 \\
\hline 2.5 & 5 & 7.4959 & 1.9951 & 0.00 \\
\hline 5 & 7.5 & 1.9949 & 0.82822 & 0.00 \\
\hline 7.5 & 10 & 0.82811 & 1.0162 & 0.00 \\
\hline 10 & 25 & 1.016 & 0.27988 & 0.00 \\
\hline 25 & 50 & 0.27943 & 18.685 & 0.00 \\
\hline 50 & 75 & 18.684 & 0.062817 & 0.00 \\
\hline 75 & 100 & 0.062232 & 0.10 \\
\hline 100 & 500 & 32.136 & 32.266 & 0.10 \\
\hline 500 & 1000 & 2.1471 & 2.2439 & 0.08 \\
\hline 1000 & 5285 & 2.5236 & 2.6513 & 0.11 \\
\hline
\end{tabular}

Fig. 12. Comparison of ENDF/B-VI.4 and JEF-2.2 Nd-143 Capture Resonance Integrals 


\section{Promethium 147}

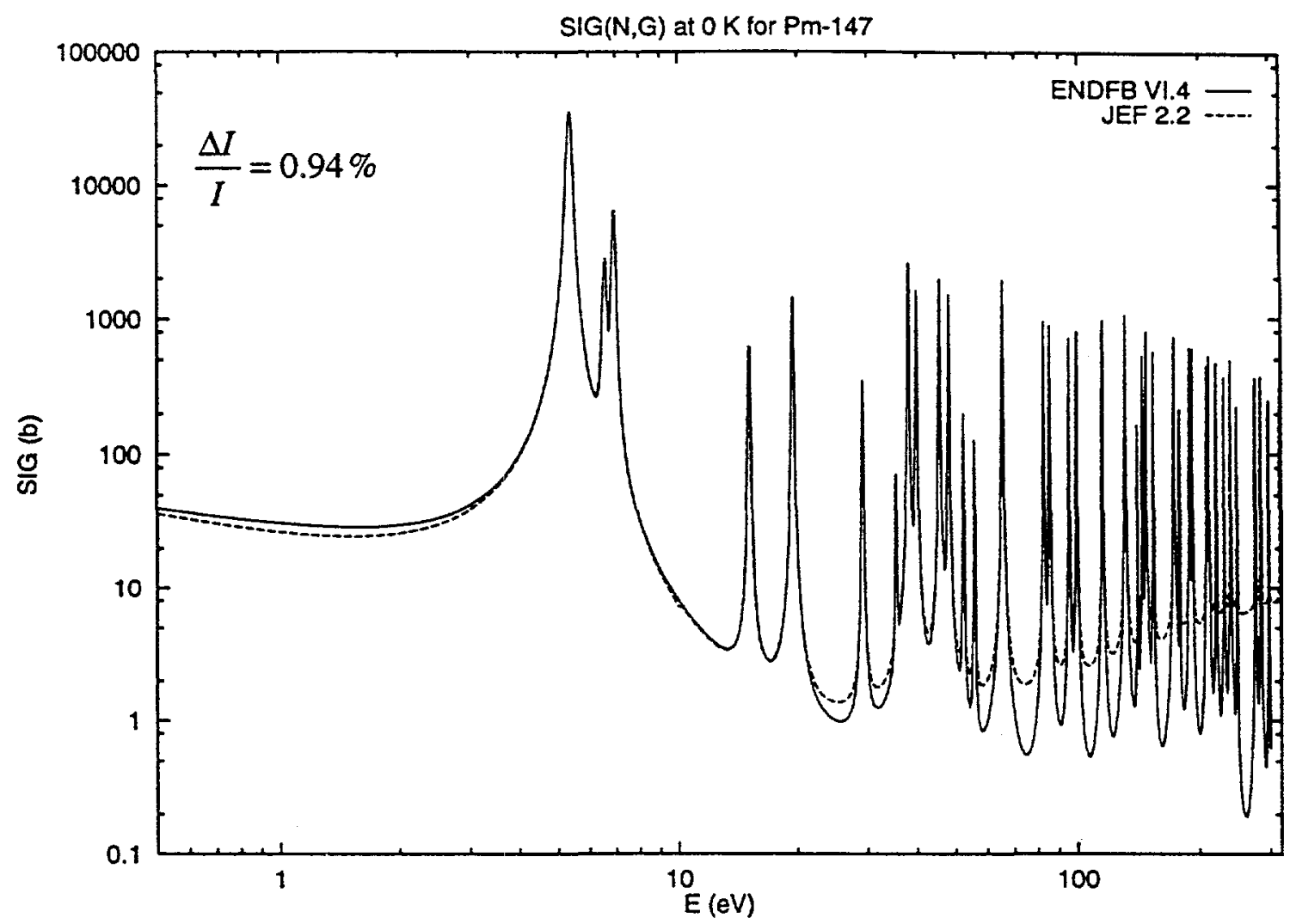

\begin{tabular}{|c|c|c|c|c|}
\hline \multicolumn{2}{|c|}{ Energy range $(\mathbf{e V})$} & I(b)-JEF & I(b)-ENDF & $\begin{array}{c}\text { Importance } \\
(\%)\end{array}$ \\
\cline { 1 - 2 } $\mathbf{E}_{\min }$ & $\mathbf{E}_{\max }$ & & 14.749 & -0.08 \\
\hline 0.5 & 0.75 & 16.619 & 14.7128 & -0.04 \\
\hline 0.75 & 1 & 7.3432 & 6.3128 & -0.16 \\
\hline 1 & 2.5 & 27.784 & 23.911 & -0.07 \\
\hline 2.5 & 5 & 89.843 & 88.292 & 1.05 \\
\hline 5 & 7.5 & 1727.6 & 1749.2 & -0.01 \\
\hline 7.5 & 10 & 6.9322 & 6.8259 & 0.02 \\
\hline 10 & 25 & 33.84 & 34.211 & 0.03 \\
\hline 25 & 50 & 78.678 & 79.326 & 0.03 \\
\hline 50 & 75 & 18.045 & 18.717 & 0.03 \\
\hline 75 & 100 & 20.546 & 21.21 & 0.21 \\
\hline 100 & 300 & 43.624 & 47.587 & \\
\hline
\end{tabular}

Fig. 13. Comparison of ENDF/B-VI.4 and JEF-2.2 Pm-147 Capture Resonance Integrals 


\section{Promethium 148m}

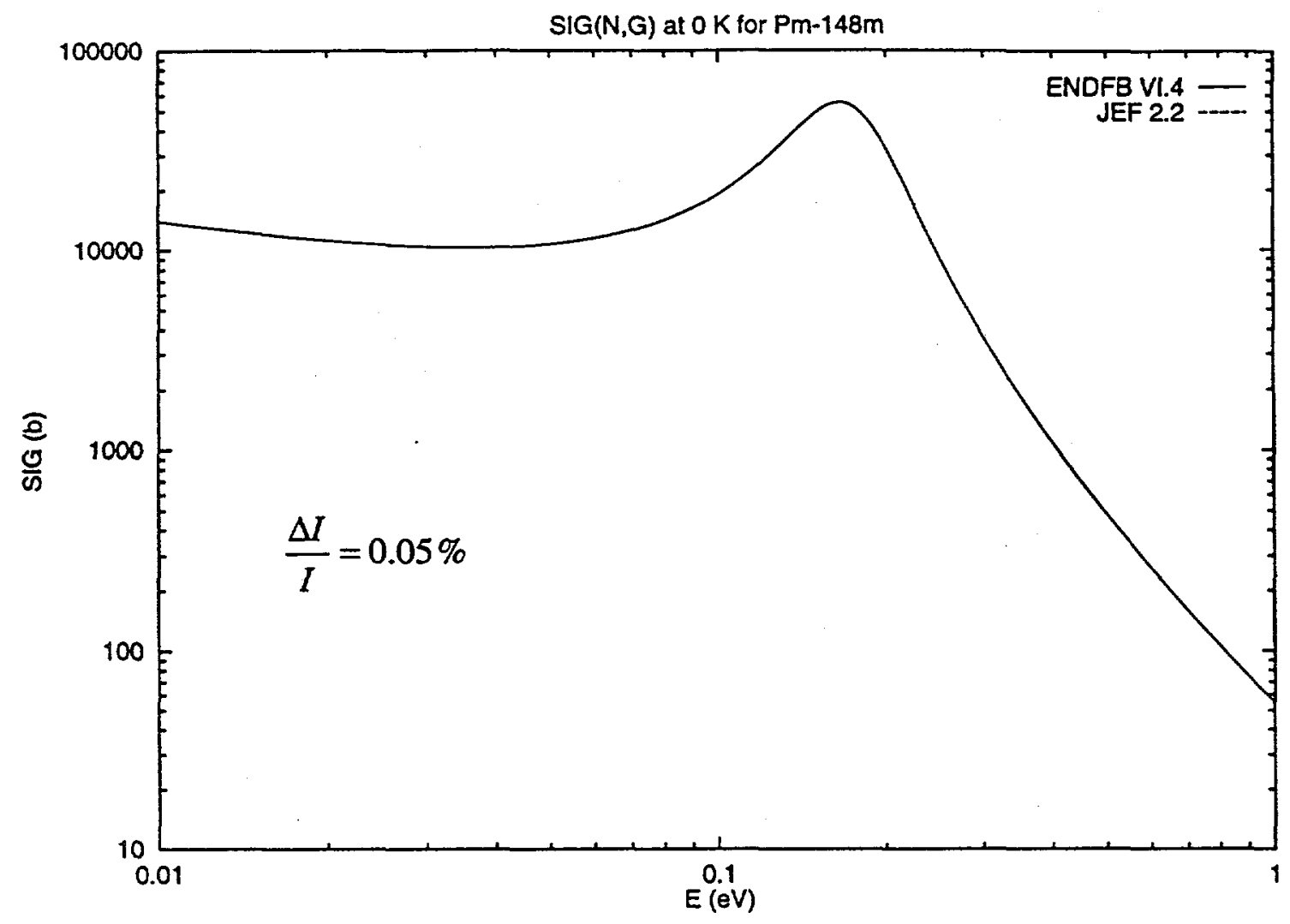

\begin{tabular}{|c|c|c|c|c|}
\hline \multicolumn{2}{|c|}{ Energy range (eV) } & \multirow{2}{*}{ I(b)-JEF } & \multirow{2}{*}{ I(b)-ENDF } & \multirow{2}{*}{$\begin{array}{c}\text { Importance } \\
(\%)\end{array}$} \\
\hline $\mathbf{E}_{\min }$ & $\mathbf{E}_{\max }$ & & & \\
\hline 0.01 & 0.5 & 58606.00 & 58633.00 & 0.05 \\
\hline 0.5 & 0.75 & 100.45 & 100.46 & 0.00 \\
\hline 0.75 & 1 & 13.08 & 13.08 & 0.00 \\
\hline
\end{tabular}

Fig. 14. Comparison of ENDF/B-VI.4 and JEF-2.2 Pm-148m Capture Resonance Integrals 


\section{Samarium 147}

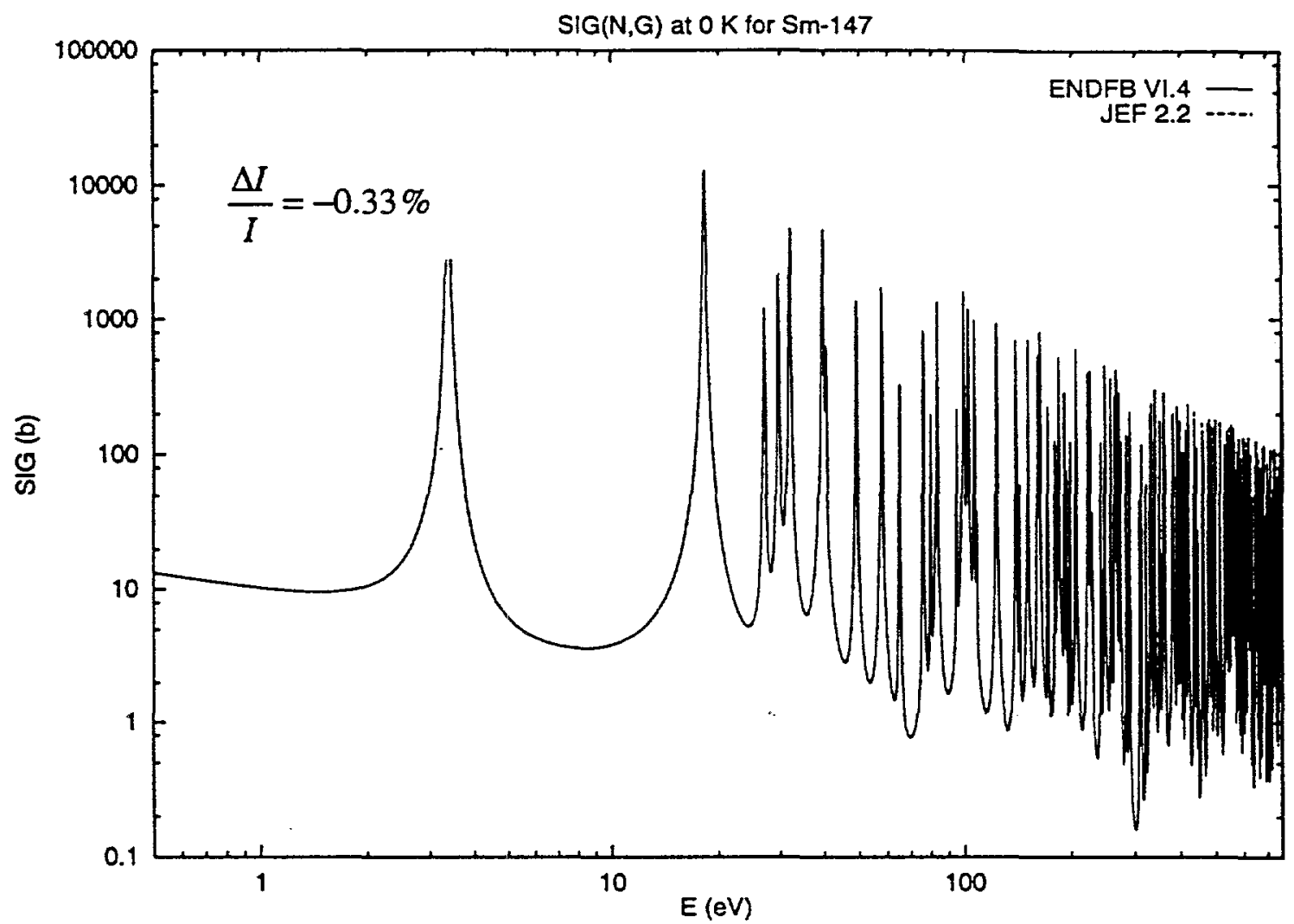

\begin{tabular}{|c|c|c|c|c|}
\hline \multicolumn{2}{|c|}{ Energy range (eV) } & I(b)-JEF & I(b)-ENDF & $\begin{array}{c}\text { Importance } \\
(\boldsymbol{\%})\end{array}$ \\
\cline { 1 - 2 } $\mathbf{E}_{\min }$ & $\mathbf{E}_{\max }$ & & & \\
\hline 0.5 & 0.75 & 5.8916 & 5.8869 & 0.00 \\
\hline 0.75 & 1 & 1.7392 & 1.7379 & 0.00 \\
\hline 1 & 2.5 & 7.6902 & 7.686 & 0.00 \\
\hline 2.5 & 5 & 206.63 & 206.63 & 0.00 \\
\hline 5 & 7.5 & 2.0661 & 2.065 & 0.00 \\
\hline 7.5 & 10 & 0.8505 & 0.85058 & 0.00 \\
\hline 10 & 25 & 255.87 & 255.89 & 0.00 \\
\hline 25 & 50 & 165.45 & 165.48 & 0.00 \\
\hline 50 & 75 & 16.6 & 16.599 & 0.00 \\
\hline 75 & 100 & 28.453 & 27.964 & -0.06 \\
\hline 100 & 500 & 72.764 & 71.011 & -0.22 \\
\hline 500 & 768.3 & 9.3676 & 9.0119 & -0.04 \\
\hline
\end{tabular}

Fig. 15. Comparison of ENDF/B-VI.4 and JEF-2.2 Sm-147 Capture Resonance Integrals 


\section{Samarium 149}

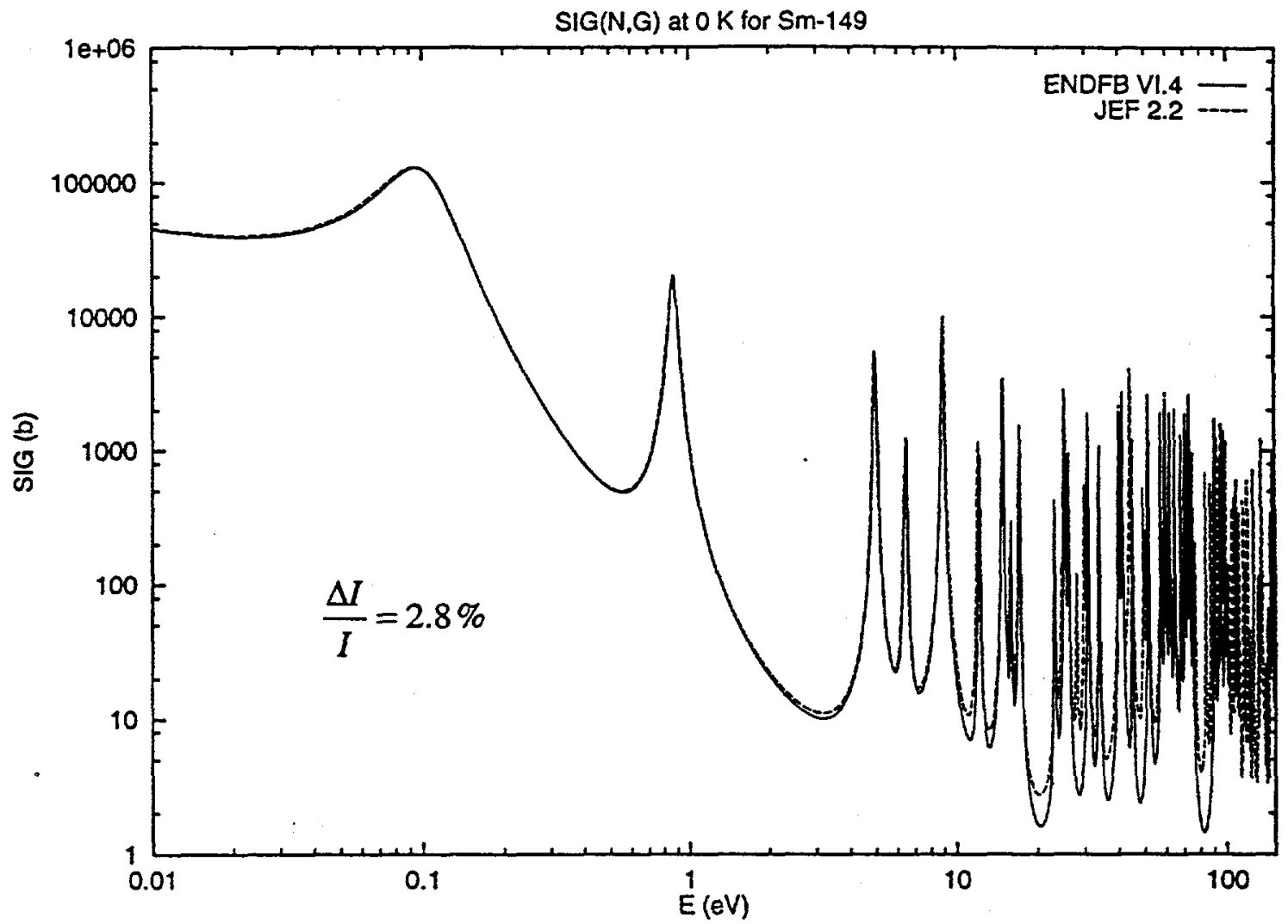

\begin{tabular}{|c|c|c|c|c|}
\hline \multicolumn{2}{|c|}{ Energy range (eV) } & \multirow{2}{*}{ I(b)-ENDF } & \multirow{2}{*}{ I(b)-JEF } & \multirow{2}{*}{$\begin{array}{c}\text { Importance } \\
(\%)\end{array}$} \\
\hline$E_{\min }$ & $\mathbf{E}_{\max }$ & & & \\
\hline 0.01 & 0.5 & 162870 & 167290 & 2.66 \\
\hline 0.5 & 0.75 & 258 & 270.72 & 0.01 \\
\hline 0.75 & 1 & 1874 & 1920.7 & 0.03 \\
\hline 1 & 2.5 & 119.72 & 125.62 & 0.00 \\
\hline 2.5 & 5 & 116.06 & 151.22 & 0.03 \\
\hline 5 & 7.5 & 105.43 & 79.223 & -0.01 \\
\hline 7.5 & 10 & 234.75 & 252.29 & 0.01 \\
\hline 10 & 25 & 105 & 104.91 & 0.00 \\
\hline 25 & 50 & 119.94 & 182.16 & 0.06 \\
\hline 50 & 75 & 115.48 & 153.83 & 0.03 \\
\hline 75 & 100 & 28.731 & 71.846 & 0.06 \\
\hline
\end{tabular}

Fig. 16. Comparison of ENDF/B-VI.4 and JEF-2.2 Sm-149 Capture Resonance Integrals 


\section{Samarium 150}

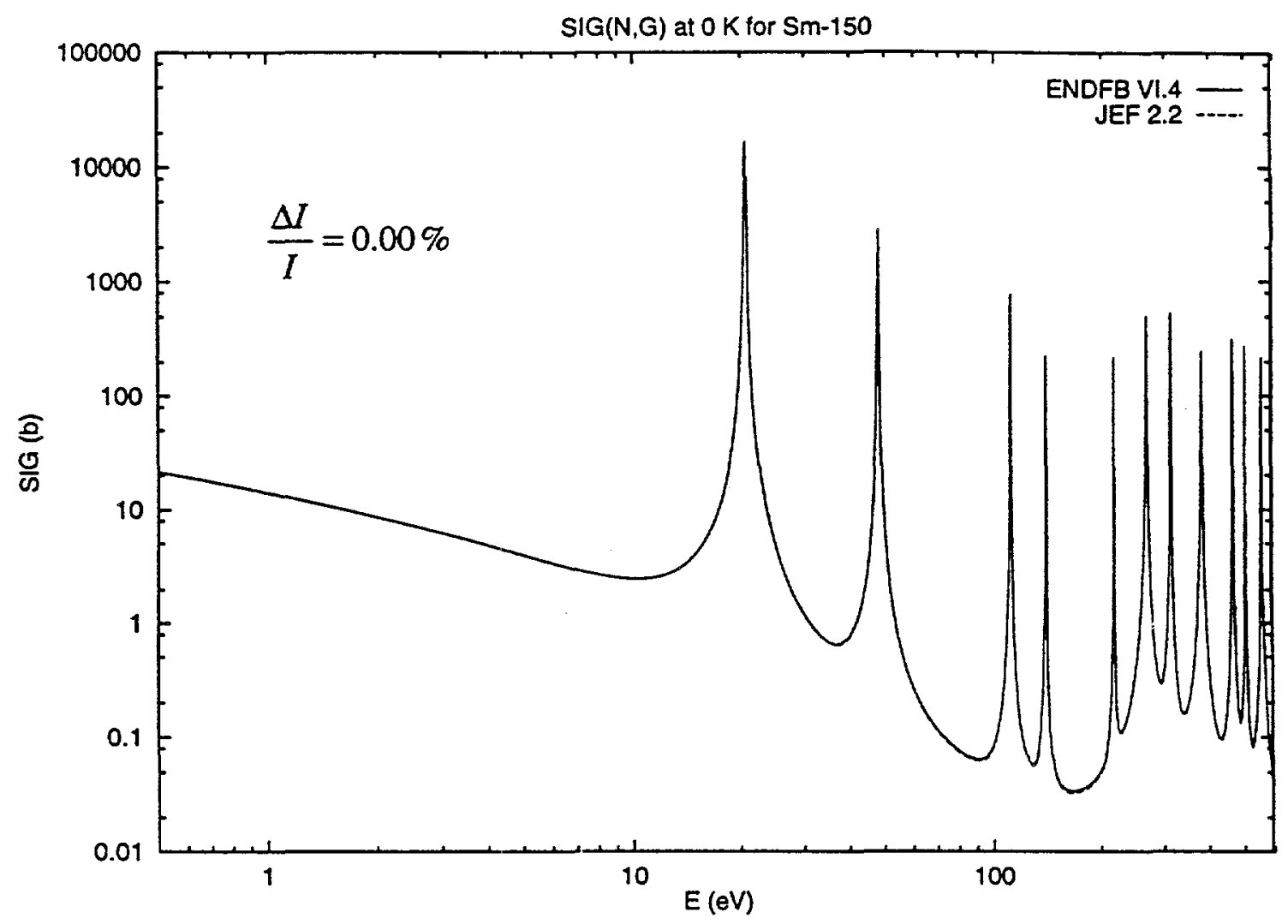

\begin{tabular}{|c|c|c|c|c|}
\hline \multicolumn{2}{|c|}{ Energy range $(\mathrm{eV})$} & I(b)-JEF & I(b)-ENDF & $\begin{array}{c}\text { Importance } \\
(\%)\end{array}$ \\
\cline { 1 - 4 } $\mathbf{E}_{\min }$ & $\mathbf{E}_{\max }$ & $(\mathbf{b})$ & 0.01 \\
\hline 0.5 & 0.75 & 8.4737 & 8.4947 & 0.00 \\
\hline 0.75 & 1 & 4.1859 & 4.1936 & 0.00 \\
\hline 1 & 2.5 & 8.5336 & 8.5495 & 0.00 \\
\hline 2.5 & 5 & 3.6478 & 3.6573 & 0.00 \\
\hline 5 & 7.5 & 1.4676 & 1.4723 & 0.00 \\
\hline 7.5 & 10 & 0.65171 & 0.65369 & -0.02 \\
\hline 10 & 25 & 259.91 & 259.86 & 0.00 \\
\hline 25 & 50 & 28.317 & 28.321 & 0.00 \\
\hline 50 & 75 & 0.28442 & 0.28538 & 0.00 \\
\hline 75 & 100 & 0.01999 & 0.020456 & 0.00 \\
\hline 100 & 500 & 13.782 & 13.781 & 0.00 \\
\hline 500 & 592.7 & 1.4116 & 1.412 & \\
\hline
\end{tabular}

Fig. 17. Comparison of ENDF/B-VI.4 and JEF-2.2 Sm-150 Capture Resonance Integrals 


\section{Samarium 152}

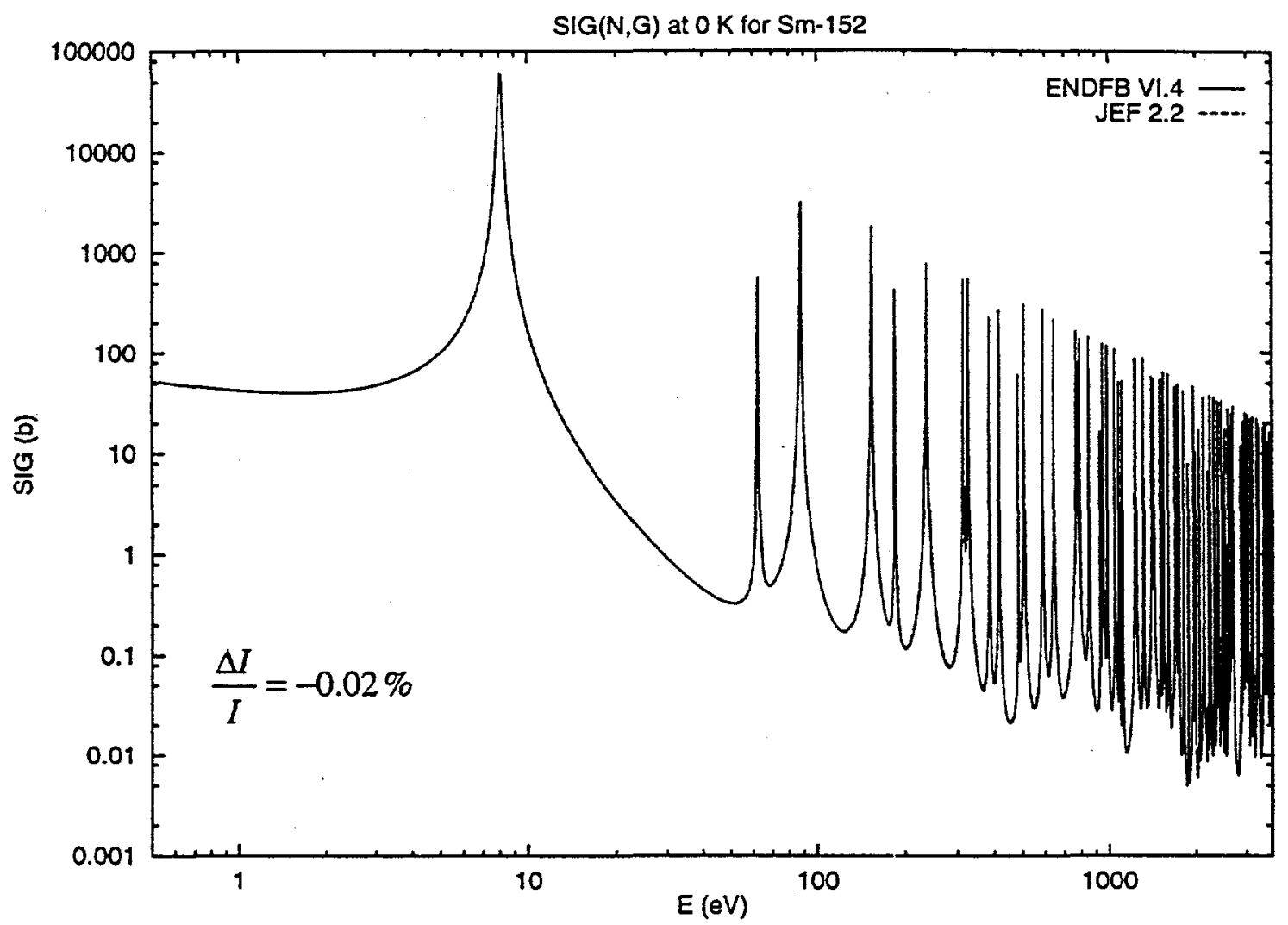

\begin{tabular}{|c|c|c|c|c|}
\hline \multicolumn{2}{|c|}{ Energy range (eV) } & I(b)-JEF & I(b)-ENDF & $\begin{array}{c}\text { Importance } \\
(\boldsymbol{\%})\end{array}$ \\
\cline { 1 - 2 } $\mathbf{E}_{\min }$ & $\mathbf{E}_{\max }$ & & 21.805 & 0.00 \\
\hline 0.5 & 0.75 & 21.809 & 14.627 & 0.00 \\
\hline 0.75 & 1 & 14.628 & 30.375 & 0.00 \\
\hline 1 & 2.5 & 30.376 & 39.887 & 0.00 \\
\hline 2.5 & 5 & 39.888 & 190.24 & 0.00 \\
\hline 5 & 7.5 & 190.24 & 2578.5 & 0.00 \\
\hline 7.5 & 10 & 2578.5 & 18.43 & 0.00 \\
\hline 10 & 25 & 18.43 & 0.43394 & 0.00 \\
\hline 25 & 50 & 0.43446 & 4.2049 & 0.00 \\
\hline 50 & 75 & 4.2009 & 26.673 & 0.00 \\
\hline 75 & 100 & 26.673 & 20.511 & -0.01 \\
\hline 100 & 500 & 20.92 & 3.743 & -0.01 \\
\hline 500 & 1000 & 3.9066 & 2.2742 & 0.00 \\
\hline 1000 & 3691.1 & 2.3882 & & \\
\hline
\end{tabular}

Fig. 18. Comparison of ENDF/B-VI.4 and JEF-2.2 Sm-152 Capture Resonance Integrals 


\section{Europium 151}

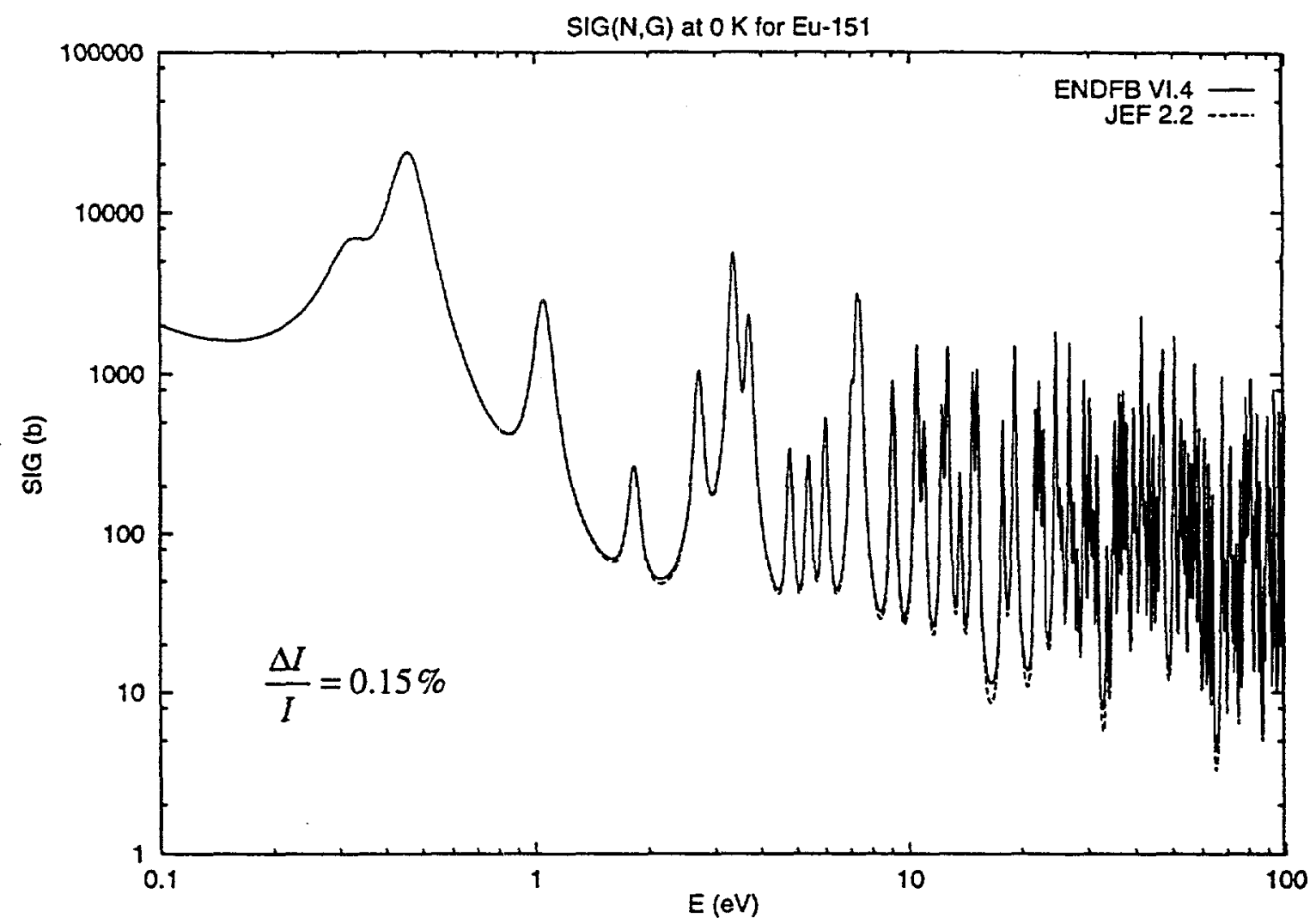

\begin{tabular}{|c|c|c|c|c|}
\hline \multicolumn{2}{|c|}{ Energy range (eV) } & \multirow{2}{*}{ I(b)-JEF } & \multirow{2}{*}{ I(b)-ENDF } & \multirow{2}{*}{$\begin{array}{c}\text { Importance } \\
(\%)\end{array}$} \\
\hline$E_{\min }$ & $\mathbf{E}_{\max }$ & & & \\
\hline 0.1 & 0.5 & 8617.4 & 8619.7 & 0.02 \\
\hline 0.5 & 0.75 & 1250.2 & 1252 & 0.02 \\
\hline 0.75 & 1 & 159.29 & 160.27 & 0.01 \\
\hline 1 & 2.5 & 373.74 & 376.73 & 0.03 \\
\hline 2.5 & 5 & 514.96 & 517.28 & 0.02 \\
\hline 5 & 7.5 & 183.95 & 185.19 & 0.01 \\
\hline 7.5 & 10 & 49.286 & 50.195 & 0.01 \\
\hline 10 & 25 & 216.56 & 219.05 & 0.02 \\
\hline 25 & 50 & 142.57 & 144.01 & 0.01 \\
\hline 50 & 75 & 62.829 & 63.314 & 0.00 \\
\hline 75 & 98.81 & 42.758 & 42.86 & 0.00 \\
\hline
\end{tabular}

Fig. 19. Comparison of ENDF/B-VI.4 and JEF-2.2 Eu-151 Capture Resonance Integrals 


\section{Europium 153}

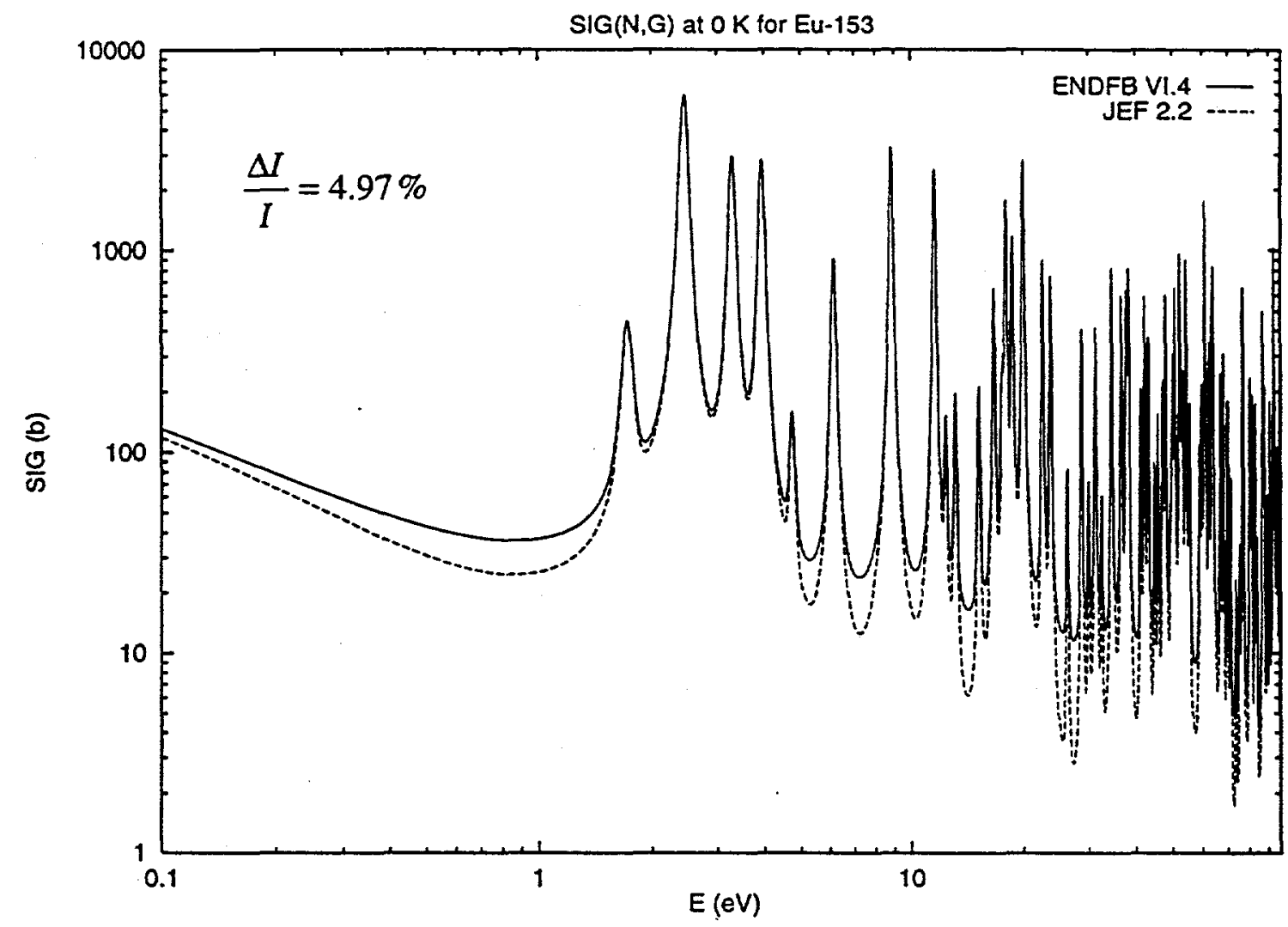

\begin{tabular}{|c|c|c|c|c|}
\hline \multicolumn{2}{|c|}{ Energy range (eV) } & \multirow{2}{*}{ I(b)-JEF } & I(b)-ENDF & $\begin{array}{c}\text { Importance } \\
(\%)\end{array}$ \\
\cline { 1 - 2 } $\mathbf{E}_{\min }$ & $\mathbf{E}_{\max }$ & & 104.63 & 1.52 \\
\hline 0.1 & 0.5 & 86.424 & 15.55 & 0.49 \\
\hline 0.5 & 0.75 & 10.676 & 11.78 & 0.39 \\
\hline 0.75 & 1 & 7.9623 & 404.09 & 0.66 \\
\hline 1 & 2.5 & 394.76 & 415.81 & 0.57 \\
\hline 2.5 & 5 & 407.73 & 43.919 & 0.36 \\
\hline 5 & 7.5 & 39.239 & 43.919 & 0.23 \\
\hline 7.5 & 10 & 94.779 & 98.012 & 0.66 \\
\hline 10 & 25 & 196.3 & 205.43 & 0.39 \\
\hline 25 & 50 & 61.922 & 67.173 & 0.13 \\
\hline 50 & 75 & 59.087 & 60.89 & 0.03 \\
\hline 75 & 97.22 & 25.471 & 25.843 & \\
\hline
\end{tabular}

Fig. 20. Comparison of ENDF/B-VI.4 and JEF-2.2 Eu-153 Capture Resonance Integrals 


\section{Gadolinium 155}

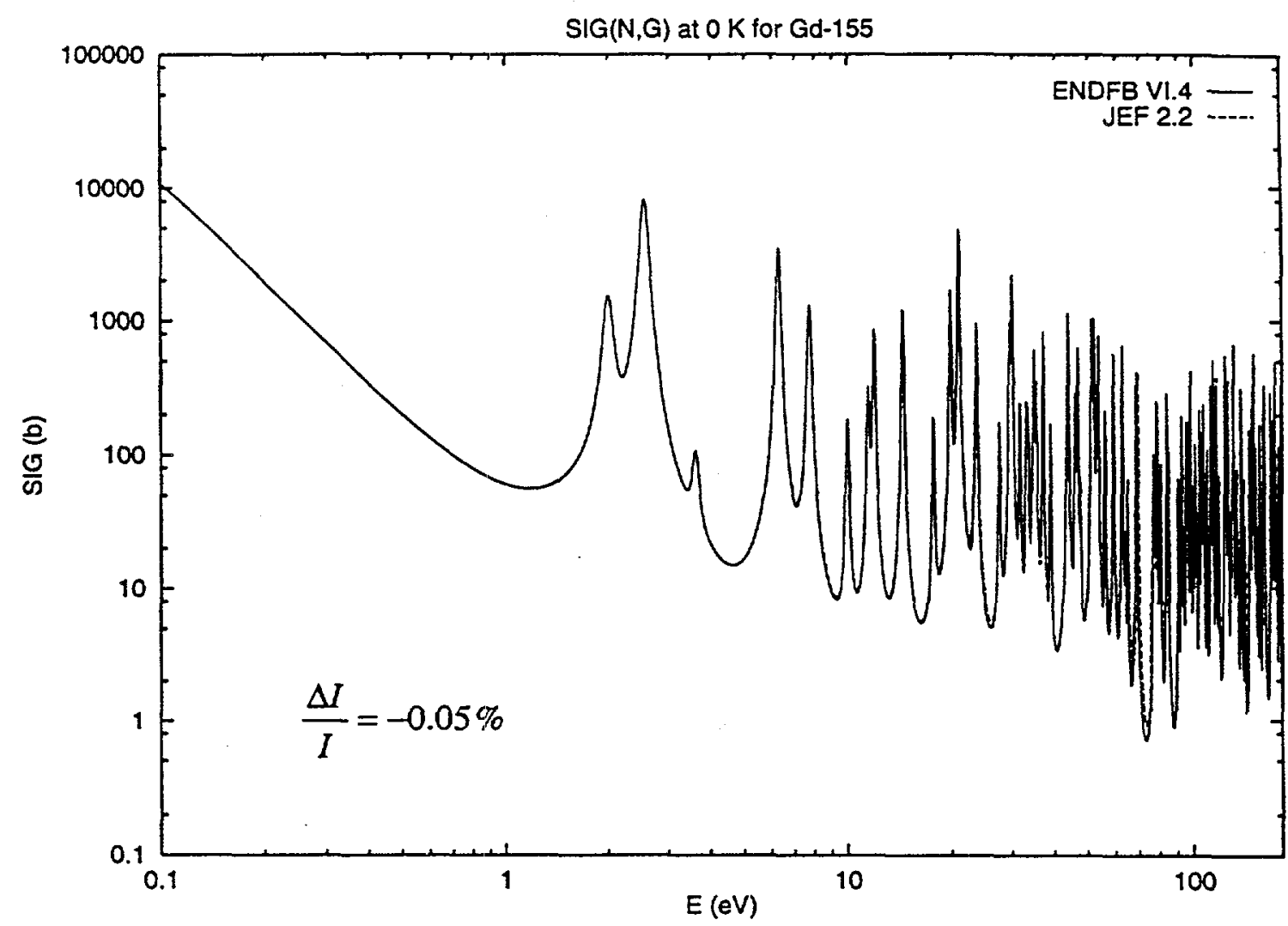

\begin{tabular}{|c|c|c|c|c|}
\hline \multicolumn{2}{|c|}{ Energy range (eV) } & I(b)-JEF & I(b)-ENDF & $\begin{array}{c}\text { Importance } \\
(\%)\end{array}$ \\
\cline { 1 - 2 } $\mathbf{E}_{\min }$ & $\mathbf{E}_{\max }$ & $(\mathbf{b})$ & 0.01 \\
\hline 0.1 & 0.5 & 4049 & 4049.4 & 0.00 \\
\hline 0.5 & 0.75 & 51.963 & 51.952 & 0.00 \\
\hline 0.75 & 1 & 21.509 & 21.517 & 0.04 \\
\hline 1 & 2.5 & 381.02 & 383.09 & 0.03 \\
\hline 2.5 & 5 & 435.79 & 437.66 & -0.09 \\
\hline 5 & 7.5 & 135.41 & 130.28 & -0.05 \\
\hline 7.5 & 10 & 46.231 & 43.349 & -0.04 \\
\hline 10 & 25 & 173.59 & 171.22 & 0.10 \\
\hline 25 & 50 & 86.048 & 91.353 & -0.01 \\
\hline 50 & 75 & 41.663 & 41.105 & 0.01 \\
\hline 75 & 100 & 12.187 & 12.506 & -0.03 \\
\hline 100 & 181.8 & 40.638 & 38.87 & \\
\hline
\end{tabular}

Fig. 21. Comparison of ENDF/B-VI.4 and JEF-2.2 Gd-155 Capture Resonance Integrals 
TABLE I. Absorption Rates for a $3.0 \mathrm{wt} \% \mathrm{UO}_{2}$ at $\mathrm{B}=50 \mathrm{GWd} / \mathrm{t}$, After 30 Years of Cooling

\begin{tabular}{|c|c||c|c|}
\hline Actinide & \% of Total Absorption & Fission Product & \% of Total Absorption \\
\hline \hline Pu-239 & 28.3 & Gd-155 & 5.51 \\
\hline U-238 & 26.0 & Nd-143 & 1.59 \\
\hline Pu-240 & 8.27 & Rh-103 & 1.46 \\
\hline U-235 & 6.57 & Sm-149 & 1.05 \\
\hline Am-241 & 4.79 & Cs-133 & 0.83 \\
\hline Pu-241 & 2.19 & Sm-151 & 0.78 \\
\hline Np-237 & 0.80 & Xe-131 & 0.74 \\
\hline $\mathrm{U}-236$ & 0.73 & Tc-99 & 0.66 \\
\hline Pu-242 & 0.68 & Eu-153 & 0.61 \\
\hline Pu-238 & 0.55 & Sm-152 & 0.58 \\
\hline Am-243 & 0.43 & Nd-152 & 0.40 \\
\hline U-234 & 0.13 & Ag-109 & 0.36 \\
\hline Cm-245 & 0.06 & Sm-150 & 0.34 \\
\hline Am-242m & 0.05 & Sm-147 & 0.32 \\
\hline Cm-244 & 0.02 & Mo-95 & 0.29 \\
\hline Cm-243 & 0.00 & Ru-101 & 0.21 \\
\hline Cm-246 & 0.00 & Pd-105 & 0.18 \\
\hline Cm-247 & 0.00 & Eu-151 & 0.15 \\
\hline & & & \\
\hline
\end{tabular}


TABLE II. Reactivity Worth Measurements in MINERVE R1-UO Calculation-Experiment Comparison (C-E)/E

\begin{tabular}{|c|c|c|c|c|c|}
\hline FP & $\begin{array}{l}\text { Mass } \\
(\mathrm{g}) \\
\end{array}$ & Matrix & $\begin{array}{c}\text { CRIBLE } \\
\text { JEF-1 }\end{array}$ & $\begin{array}{c}\text { CRISTAL } \\
\text { JEF-2 }\end{array}$ & $\begin{array}{c}\text { Exp. } \\
\text { unc. }(1 \sigma)\end{array}$ \\
\hline $\mathrm{Sm}$ & 0.026 & $\mathrm{UO}_{2}$ sintered & $-6.6 \%$ & $-5.2 \%$ & $4 \%$ \\
\hline $\mathrm{Sm}-149$ & 0.004 & $\mathrm{UO}_{2}$ sintered & $-8.0 \%$ & $-6.6 \%$ & $4 \%$ \\
\hline $\mathrm{Sm}-147$ & 1.008 & $\mathrm{UO}_{2}$ sintered & $10.4 \%$ & $10.2 \%$ & $8 \%$ \\
\hline $\mathrm{Sm}-152$ & 1.586 & $\mathrm{UO}_{2}$ sintered & $5.4 \%$ & $0.6 \%$ & $4 \%$ \\
\hline $\mathrm{Nd}$ & 3.602 & $\mathrm{UO}_{2}$ sintered & $-2.4 \%$ & $1.4 \%$ & $4 \%$ \\
\hline Nd-143 & 0.574 & $\mathrm{UO}_{2}$ sintered & $-11.7 \%$ & $-9.9 \%$ & $4 \%$ \\
\hline $\mathrm{Nd}-145$ & 2.325 & $\mathrm{UO}_{2}$ sintered & $6.9 \%$ & $5.7 \%$ & $4 \%$ \\
\hline $\mathrm{Gd}-155$ & 0.008 & $\mathrm{UO}_{2}$ sintered & $-0.6 \%$ & $-3.5 \%$ & $4 \%$ \\
\hline Eu-153 & 0.431 & $\mathrm{UO}_{2}$ sintered & $-0.2 \%$ & $-1.4 \%$ & $4 \%$ \\
\hline Tc-99 & 2.142 & $\mathrm{UO}_{2}$ non-sintered & $31.1 \%$ & $16.2 \%$ & $4 \%$ \\
\hline $\mathrm{Rh}-103$ & 0.376 & $\mathrm{UO}_{2}$ non-sintered & $14.9 \%$ & $12.2 \%$ & $4 \%$ \\
\hline Cs-133 & 0.378 & $\mathrm{UO}_{2}$ non-sintered & $2.2 \%$ & $-1.4 \%$ & $4 \%$ \\
\hline Ag-109 & 0.640 & $\mathrm{UO}_{2}$ non-sintered & $18.3 \%$ & $4.4 \%$ & $4 \%$ \\
\hline Ag-109 & 0.073 & $\mathrm{UO}_{2}$ non-sintered & $7.3 \%$ & $-2.3 \%$ & $4 \%$ \\
\hline Cs-133 & 2.250 & $\mathrm{Al}_{2} \mathrm{O}_{3}$ & $24.3 \%$ & $15.9 \%$ & $6 \%$ \\
\hline $\mathrm{Ag}$ & 1.105 & $\mathrm{Al}_{2} \mathrm{O}_{3}$ & $14.3 \%$ & $2.2 \%$ & $4 \%$ \\
\hline
\end{tabular}


TABLE III. Number Densities for the DRAGON CERES Model

Medium:water

$\mathrm{H}$

O

Medium:MINERVE fuel

$\mathrm{U}-235: 6.826 \mathrm{E}-4$

$\mathrm{U}-238: 2.2071 \mathrm{E}-2$

O-16:4.5507E-2

Medium:MINERVE clad (homogenized)

Al-27:4.64688E-2

H:6.777317E-3

$\mathrm{O}: 3.388680 \mathrm{E}-3$

Medium:Sample clad (homogenized)

$Z_{r}$ (nat):3.21040E-2

Medium:Sample (sintered)

U-235:1.592731E-4

$\mathrm{U}-238: 2.25940 \mathrm{E}-2$

O-16:4.55070E-2

Fission products (when present)

Ag-109 (low)8.044240E-5

Ag-109 (high)7.05248E-4

Cs-1333.413730E-4

Eu-1533.383560E-4

Gd-1556.199360E-6

$\mathrm{Rh}-1034.384690 \mathrm{E}-4$

Sm-1478.236290E-4

Sm-1493.224500E-6

Sm-1524.6306600E-4

Nd-1434.821300E-4

Nd-1451.925940E-3

Tc-992.5988E-3 
TABLE IV. Results of the JEF Pin Cell Benchmark

Reaction rates are normalized to 1 source neutron.

Reaction rates are given in pcm's.

MCNP results are from [Ref. 7].

Group boundaries are $9100 \mathrm{ev}$ and $4 \mathrm{eV}$

\begin{tabular}{|c|c|c|c|c|}
\hline Quantity & Group & MCNP Results & $\begin{array}{c}\text { VIM Results } \\
\text { (track length estimator) }\end{array}$ & $\begin{array}{c}\text { Difference } \\
\text { VIM-MCNP }\end{array}$ \\
\hline $\mathrm{k}_{\mathrm{eff}}$ & & 1.39011 & 1.38780 & -220 \\
\hline $\mathrm{H}_{2} \mathrm{O}+\mathrm{O}$ capture & $\begin{array}{c}1 \\
2 \\
3 \\
\text { total }\end{array}$ & $\begin{array}{r}469 \\
188 \\
5547 \\
6204\end{array}$ & 6211 & +7 \\
\hline $\mathrm{Zr}$ capture & $\begin{array}{c}1 \\
2 \\
3 \\
\text { total }\end{array}$ & $\begin{array}{r}67 \\
282 \\
301 \\
650\end{array}$ & 694 & +44 \\
\hline U5 fission & $\begin{array}{c}1 \\
2 \\
3 \\
\text { total }\end{array}$ & $\begin{array}{r}687 \\
4117 \\
48996 \\
53800\end{array}$ & $\begin{array}{r}688 \\
4101 \\
48916 \\
53705\end{array}$ & -95 \\
\hline U5 capture & $\begin{array}{c}1 \\
2 \\
3 \\
\text { total }\end{array}$ & $\begin{array}{r}110 \\
2251 \\
8540 \\
10901\end{array}$ & $\begin{array}{r}114 \\
2242 \\
8534 \\
10890\end{array}$ & -11 \\
\hline U5 absorption & total & 64701 & 64595 & -106 \\
\hline U8 fission & $\begin{array}{c}1 \\
2 \\
\text { total }\end{array}$ & $\begin{array}{r}2796 \\
1 \\
2797\end{array}$ & $\begin{array}{r}2790 \\
1 \\
2791\end{array}$ & -6 \\
\hline U8 capture & $\begin{array}{c}1 \\
2 \\
3 \\
\text { total }\end{array}$ & $\begin{array}{r}2134 \\
15237 \\
8276 \\
25647\end{array}$ & $\begin{array}{r}2243 \\
15340 \\
8277 \\
25860\end{array}$ & +213 \\
\hline U8 absorption & total & 28444 & 28651 & +207 \\
\hline U5 production & $\begin{array}{c}1 \\
2 \\
3 \\
\text { total }\end{array}$ & $\begin{array}{r}1759 \\
10019 \\
119389 \\
131167\end{array}$ & $\begin{array}{r}1757 \\
9980 \\
119260 \\
131000\end{array}$ & -167 \\
\hline U8 production & $\begin{array}{c}1 \\
2 \\
\text { total }\end{array}$ & $\begin{array}{r}7753 \\
3 \\
7756\end{array}$ & $\begin{array}{r}7784 \\
3 \\
7787\end{array}$ & +31 \\
\hline Total absorption & & 99999 & 100151 & +157 \\
\hline Total production & & 138972 & 138787 & -185 \\
\hline
\end{tabular}


TABLE V. JEF Pin Cell Fission Product Worth

\begin{tabular}{|c|c|c|c|c|c|c|c|}
\hline Isotope & $\begin{array}{c}\# \\
\text { Density }\end{array}$ & $\begin{array}{c}\text { B-VI } \\
\text { VIM Worth }\end{array}$ & $\begin{array}{c}\text { B-VI } \\
\text { DRAGON } \\
\text { Worth }\end{array}$ & $\begin{array}{c}\Delta \\
(\%)\end{array}$ & $\begin{array}{c}\text { JEF-2.2 } \\
\text { VIM Worth }\end{array}$ & $\begin{array}{c}\text { JEF-2.2 } \\
\text { DRAGON } \\
\text { Worth }\end{array}$ & $\begin{array}{c}\Delta \\
(\%)\end{array}$ \\
\hline Ag-109 & $2 \mathrm{E}-4$ & $-5.525 \mathrm{E}-2$ & $-5.835 \mathrm{E}-2$ & +5.6 & $-5.525 \mathrm{E}-2$ & $-5.851 \mathrm{E}-2$ & +5.9 \\
\hline Ag-109 ss & & & $-5.449 \mathrm{E}-2$ & -1.4 & & $-5.465 \mathrm{E}-2$ & -1.1 \\
\hline Cs-133 & $1 E-3$ & $-7517 \mathrm{E}-2$ & $-8.652 \mathrm{E}-2$ & +15 & $-7.573 \mathrm{E}-2$ & $-8.799 \mathrm{E}-2$ & +16 \\
\hline Cs-133 ss & & & $-7.401 \mathrm{E}-2$ & -1.5 & & $-7.521 \mathrm{E}-2$ & -0.7 \\
\hline Eu-153 & $1 \mathrm{E}-4$ & $-6.694 \mathrm{E}-2$ & $-6.869 \mathrm{E}-2$ & +2.6 & $-6.403 E-2$ & $-6.517 \mathrm{E}-2$ & +1.8 \\
\hline Eu-153 ss & & & $-6.954 \mathrm{E}-2$ & +3.9 & . & $-6.539 E-2$ & +2.1 \\
\hline Gd-155 & $1 E-6$ & $-4.32 \mathrm{E}-2$ & & & $-4.369 \mathrm{E}-2$ & & \\
\hline Gd-155 ss & & & & & & $-4.472 \mathrm{E}-2$ & +2.4 \\
\hline $\mathrm{Nd}-143$ & $1 \mathrm{E}-4$ & $-3737 \mathrm{E}-2$ & $-3.785 \mathrm{E}-2$ & +1.3 & $-3.776 \mathrm{E}-2$ & $-3.776 \mathrm{E}-2$ & 0 \\
\hline $\mathrm{Nd}-145$ & $2 \mathrm{E}-4$ & $-1.871 \mathrm{E}-2$ & $-2.089 \mathrm{E}-2$ & +12 & $-1.827 \mathrm{E}-2$ & $-2.079 \mathrm{E}-2$ & +13.8 \\
\hline Nd-145 ss & & & $-1.862 \mathrm{E}-2$ & -0.5 & & $-1.851 \mathrm{E}-2$ & +1.3 \\
\hline Rh-103 & $1 \mathrm{E}-4$ & $-4.352 \mathrm{E}-2$ & $-4.342 \mathrm{E}-2$ & -0.2 & $-4.350 \mathrm{E}-2$ & $-4.338 \mathrm{E}-2$ & -0.3 \\
\hline Rh-103 ss & & & $-4.346 \mathrm{E}-2$ & -0.1 & & $-4.344 \mathrm{E}-2$ & -0.1 \\
\hline Sm-147 & $2 E-4$ & $-4.249 \mathrm{E}-2$ & $-5.112 \mathrm{E}-2$ & +20 & $-4.278 \mathrm{E}-2$ & $-5.142 \mathrm{E}-2$ & +20 \\
\hline $\mathrm{Sm}-147 \mathrm{ss}$ & & & $-4.296 \mathrm{E}-2$ & +1.1 & & $-4.323 E-2$ & +1.1 \\
\hline Sm-149 & $1 \mathrm{E}-6$ & $-7.930 \mathrm{E}-2$ & $-8.278 \mathrm{E}-2$ & +4.4 & $-8.434 \mathrm{E}-2$ & $-8.513 E-2$ & +0.9 \\
\hline \multicolumn{8}{|l|}{ Sm-149 ss } \\
\hline Tc-99 & $5 E-4$ & $-3.340 \mathrm{E}-2$ & $-3.866 \mathrm{E}-2$ & +16 & $-3.504 \mathrm{E}-2$ & $-3.757 \mathrm{E}-2$ & +7.2 \\
\hline Tc-99 ss & & & $-3.402 \mathrm{E}-2$ & +1.9 & & $-3.421 \mathrm{E}-2$ & -2.4 \\
\hline $\mathrm{Sm}-152$ & $1 \mathrm{E}-4$ & $-4.958 \mathrm{E}-2$ & $-5.589 \mathrm{E}-2$ & +13 & $-4.955 \mathrm{E}-2$ & $-5.603 \mathrm{E}-2$ & +13 \\
\hline Sm-152 ss & & & $-5.329 \mathrm{E}-2$ & +7.5 & & $-5.329 \mathrm{E}-2$ & +7.6 \\
\hline
\end{tabular}

VIM (one sigma) statistical uncertainty on worth is $0.050 \mathrm{E}-2$ 
TABLE VI. CERES Analysis Results

\begin{tabular}{|l|c|c|c|c|c|c|c|}
\hline Isotope & $\begin{array}{c}\text { Mass } \\
\text { (g) }\end{array}$ & $\begin{array}{c}\text { B-VI } \\
\text { no ss }\end{array}$ & $\begin{array}{c}\text { B-VI ss } \\
\text { Worth }\end{array}$ & $\begin{array}{c}\text { JEF-2 no } \\
\text { ss Worth }\end{array}$ & $\begin{array}{c}\text { C/E JEF } \\
\text { (no ss) }\end{array}$ & $\begin{array}{c}\text { C/E B-VI } \\
\text { (ss) }\end{array}$ & $\begin{array}{c}\text { Experimental } \\
\text { Uncertainty* }\end{array}$ \\
\hline Ag-109 & 0.073 & $-9.197 \mathrm{E}-4$ & $-8.732 \mathrm{E}-4$ & $-9.186 \mathrm{E}-4$ & 0.977 & 0.929 & $10 \%$ \\
\hline Ag-109 & 0.640 & $-5.077 \mathrm{E}-3$ & $-4.525 \mathrm{E}-3$ & $-5.083 \mathrm{E}-3$ & 104.4 & 0.929 & $4.3 \%$ \\
\hline Cs-133 & 0.378 & $-1.079 \mathrm{E}-3$ & $-9.289 \mathrm{E}-3$ & $-1.143 \mathrm{E}-3$ & 0.991 & 0.805 & $7.3 \%$ \\
\hline Eu-153 & 0.431 & $-6.614 \mathrm{E}-3$ & $-6.446 \mathrm{E}-3$ & $-6.269 \mathrm{E}-3$ & 0.985 & 1.013 & $4.0 \%$ \\
\hline Gd-155 & 0.008 & $-7.251 \mathrm{E}-3$ & same & $-7.262 \mathrm{E}-4$ & 0.975 & 0.978 & $2.9 \%$ \\
\hline Nd-143 & 0.574 & $-5.241 \mathrm{E}-3$ & same & $-5.206 \mathrm{E}-4$ & 0.929 & 0.935 & $4.0 \%$ \\
\hline Nd-145 & 2.325 & $-5.181 \mathrm{E}-3$ & $-4.090 \mathrm{E}-3$ & $-5.146 \mathrm{E}-4$ & 1.197 & 0.951 & $3.8 \%$ \\
\hline Rh-103 & 0.376 & $-5.070 \mathrm{E}-3$ & $-5.061 \mathrm{E}-3$ & $-5.057 \mathrm{E}-4$ & 1.116 & 1.117 & $4.0 \%$ \\
\hline Sm-147 & 1.008 & $-5.638 \mathrm{E}-3$ & $-4.284 \mathrm{E}-3$ & $-5.665 \mathrm{E}-4$ & 1.102 & 0.833 & $8.0 \%$ \\
\hline Sm-149 & 0.004 & $-7.372 \mathrm{E}-3$ & same & $-7.541 \mathrm{E}-4$ & 0.940 & 0.916 & $4.0 \%$ \\
\hline Sm-152 & 0.586 & $-5.699 \mathrm{E}-3$ & $-5.222 \mathrm{E}-3$ & $-5.700 \mathrm{E}-3$ & 1.013 & 0.916 & $4.0 \%$ \\
\hline Tc-99 & 2.142 & $-4.3451 \mathrm{E}-3$ & $-3.8738 \mathrm{E}-3$ & -4.52481 & 1.158 & 0.991 & $3.8 \%$ \\
\hline Cs-133 & 3.076 & $-6.029 \mathrm{E}-3$ & $-5.036 \mathrm{E}-3$ & $-6.047 \mathrm{E}-3$ & 1.242 & 1.034 & $3.2 \%$ \\
\hline Mo-95 & 3.650 & $-4.066 \mathrm{E}-3$ & $-3.185 \mathrm{E}-3$ & $-3.947 \mathrm{E}-5$ & 1.257 & 1.014 & $3.4 \%$ \\
\hline
\end{tabular}

*A. Santamarima, CEA, private communication.[8] 
TABLE VII. Summary of Available CERES Fission Product Analyses

\begin{tabular}{|c|c|c|c|c|c|}
\hline \multirow{2}{*}{ FP } & \multicolumn{4}{|c|}{ (C-E)/E } & \multirow{2}{*}{} \\
\cline { 2 - 5 } & \multicolumn{2}{|c|}{ DIMPLE II (1) } & \multicolumn{2}{c|}{ MINERVE } \\
\cline { 2 - 5 } & $\begin{array}{c}\text { B-V } \\
\text { SCALE }\end{array}$ & $\begin{array}{c}\text { JEF-2.2 } \\
\text { WIMS }\end{array}$ & $\begin{array}{c}\text { JEF-2.2 } \\
\text { WIMS }\end{array}$ & $\begin{array}{c}\text { B-VI } \\
\text { DRAGON }\end{array}$ & \multirow{2}{*}{ gi $_{\text {f }}$ (1) } \\
\hline Sm-147 & $-2 \%$ & $1 \%$ & $3 \%$ & $-17 \%$ & 0.97 \\
\hline Sm-147 & $-3 \%$ & $-5 \%$ & $-2 \%$ & $-9 \%$ & 1.02 \\
\hline Sm-152 & $-1 \%$ & $-1 \%$ & $-2 \%$ & $-7 \%$ & 0.99 \\
\hline Nd-143 & $-1 \%$ & $-1 \%$ & $-4 \%$ & $-7 \%$ & 1.01 \\
\hline Nd-145 & $1 \%$ & $-1 \%$ & $0 \%$ & $-5 \%$ & 0.99 \\
\hline Ag-109 & $4 \%$ & $2 \%$ & $3 \%$ & $-7 \%$ & 0.96 \\
\hline Gd-155 & $4 \%$ & $4 \%$ & $2 \%$ & $-2 \%$ & 0.96 \\
\hline Tc-99 & $5 \%$ & $7 \%$ & $-3 \%$ & $-1 \%$ & 0.93 \\
\hline Mo-95 & $19 \%$ & $6 \%$ & $11 \%$ & $1 \%$ & 0.81 \\
\hline Rh-103 & $16 \%$ & $11 \%$ & $11 \%$ & $12 \%$ & 0.84 \\
\hline Cs-133 & $12 \%$ & $12 \%$ & $7 \%$ & $3 \%$ & 0.88 \\
\hline Eu-153 & $19 \%$ & $-9 \%$ & $-10 \%$ & $1 \%(3)$ & 0.81 \\
\hline Result & N.T & & & \\
\hline
\end{tabular}

(1) Results from N. T. Gulliford

(2) ANL results

(3) Corrected for Eu-151 impurities

$$
\begin{aligned}
& g_{i}=1-\max \left(\frac{C-E}{E}\right) \\
& g_{i}=\text { is a conservative correction factor to apply to calculated worth. }
\end{aligned}
$$


TABLE VIII. Overview of the Comparison Between ENDF/B-VI and JEF-2.2

\begin{tabular}{|c|c|c|c|c|c|c|c|}
\hline \multirow{2}{*}{ Isotope } & \multicolumn{3}{|c|}{ ENDF-B-VI.4 } & \multicolumn{3}{|c|}{ JEF-2.2 } & \multirow{2}{*}{$\frac{\Delta \mathrm{I}}{\mathrm{I}}(\%)$} \\
\hline & Form. & $\mathrm{E}_{\max }(\mathrm{eV})$ & I & Form. & $\mathrm{E}_{\text {mas }}(\mathrm{eV})$ & I & \\
\hline Mo-95 & SL & 2188.2 & 108.59 & ML & 2168.4 & 107.55 & 0.97 \\
\hline Tc-99 & SL & 800 & 336.45 & ML & 1153 & 291.45 & -13.18 \\
\hline Ru-101 & ML & 1000 & 102.22 & ML & 1044.26 & 102.22 & 0.00 \\
\hline $\mathrm{Rh}-103$ & SL & 1500 & 1012.81 & ML & 2070 & 1014.44 & 0.16 \\
\hline Ag-109 & ML & 2508.98 & 1473.47 & ML & 984 & 1473.59 & -0.01 \\
\hline Cs-133 & SL & 2500 & 377.07 & ML & 3511 & 434.77 & 15.30 \\
\hline Nd-143 & ML & 5285 & 124.06 & ML & 5521 & 124.47 & 0.33 \\
\hline Pm-147 & ML & 300 & 2070.85 & ML & 319 & 2090.34 & 0.94 \\
\hline $\mathrm{Pm}-148 \mathrm{~m}$ & SL & 1 & 58746.54 & $\mathrm{ML}$ & 1 & 58719.53 & 0.05 \\
\hline Sm-147 & ML & 1000 & 770.81 & ML & 768.70 & 773.37 & -0.33 \\
\hline Sm-149 & ML & 100 & 165947.11 & ML & 150.50 & 170602.52 & 2.81 \\
\hline Sm-150 & $\mathrm{ML}$ & 1600 & 330.70 & ML & 592.70 & 330.69 & 0.00 \\
\hline $\mathrm{Eu}-152$ & ML & 5025 & 2951.70 & ML & 3691.10 & 2952.39 & -0.02 \\
\hline $\mathrm{Eu}-151$ & ML & 98.81 & 11630.60 & ML & 98.81 & 11613.54 & 0.15 \\
\hline $\mathrm{Eu}-153$ & ML & 97.22 & 1453.13 & $\mathrm{ML}$ & 97.22 & 1384.35 & 4.97 \\
\hline Gd-155 & ML & 183.43 & 5472.30 & ML & 181.80 & 5475.05 & -0.05 \\
\hline
\end{tabular}

$\mathrm{SL}=$ Single Level Breit Wigner

$\mathrm{ML}=$ Multiple Level Breit Wigner 
TABLE IX. Conservative Correction Factors for Fission Product Concentrations

\begin{tabular}{|c|c|c|}
\hline Isotope & $\begin{array}{c}\text { Factor for } \\
\text { 27 BURNUPLIB }\end{array}$ & $\begin{array}{c}\text { Factor for } \\
\text { 44 GROUPNDF5 }\end{array}$ \\
\hline Sm-149 & $0.5^{\mathrm{a}}$ & $0.5^{\mathrm{a}}$ \\
\hline Nd-143 & 0.930 & 0.962 \\
\hline Gd-155 & $0.7^{\mathrm{a}}$ & 0.524 \\
\hline Rd-103 & $0.8^{\mathrm{b}}$ & $0.8^{\mathrm{b}}$ \\
\hline Cs-133 & 0.928 & 0.907 \\
\hline Tc-99 & 0.594 & 0.590 \\
\hline Sm-152 & 0.775 & 0.755 \\
\hline Sm-147 & 0.675 & 0.695 \\
\hline Nd-145 & 0.981 & 0.973 \\
\hline Mo-95 & $0.8^{\mathrm{b}}$ & $0.8^{\mathrm{b}}$ \\
\hline Eu-153 & 0.601 & 0.641 \\
\hline Ag-109 & $0.8^{5}$ & $0.8^{\mathrm{b}}$ \\
\hline
\end{tabular}

a: In these cases, the statistical treatment produced negative concentrations. $\mathrm{f}$ was taken to be the lowest of all available C/Es.

b: $\quad$ No value is given in reference. $f$ was estimated from unpublished non U.S. results. 
TABLE X. $4.5 \%$ Enriched Fuel at $50 \mathrm{GWd} / \mathrm{t}-30$ y Cooling

Total FP Absorption: $17.6 \mathrm{E}-2$

\begin{tabular}{|c|c|c|c|c|}
\hline Isotope & $\mathrm{W}=$ Worth $(\%)$ & $\begin{array}{c}\mathrm{f}_{\mathrm{i}}: \text { Concentration } \\
\text { Correction }\end{array}$ & $\begin{array}{c}\mathrm{g}_{\mathrm{i}}: \text { Worth } \\
\text { Correction }\end{array}$ & $\begin{array}{c}\text { Minimal Worth } \\
\text { Wxfixgi }\end{array}$ \\
\hline Gd-155 & 3.93 & 0.7 & 0.96 & 2.64 \\
\hline Nd-143 & 1.55 & 0.93 & 1.01 & 1.46 \\
\hline Rh-103 & 1.33 & 0.8 & 0.84 & 0.89 \\
\hline Sm-149 & 1.03 & 0.5 & 1.02 & 0.53 \\
\hline Cs-133 & .80 & 0.93 & 0.88 & 0.65 \\
\hline Tc-99 & .64 & 0.59 & 0.93 & 0.35 \\
\hline Sm-152 & .52 & 0.78 & 0.99 & 0.40 \\
\hline Eu-153 & .50 & 0.60 & 0.81 & 0.24 \\
\hline Nd-145 & .38 & 0.98 & 0.99 & 0.37 \\
\hline Sm-147 & .35 & 0.67 & 0.97 & 0.23 \\
\hline Mo-95 & .28 & 0.8 & 0.81 & 0.18 \\
\hline Ag-109 & .28 & 0.8 & 0.96 & 0.22 \\
\hline ToTALs & 11.59 & & & 8.16 \\
\hline
\end{tabular}

Total FP Worths: $17.6 \%$

From Experimental Data: $8.16 \%$ are known 
TABLE XI. $3.0 \%$ Enriched Fuel at $10 \mathrm{GWd} / \mathrm{t}-30 \mathrm{y}$ Cooling

Total FP Absorption: 7.12\%

\begin{tabular}{|c|c|c|c|c|}
\hline Isotope & $\mathrm{W}=$ Worth $(\%)$ & $\begin{array}{c}\mathrm{f}_{\mathrm{i}}: \text { Concentration } \\
\text { Correction }\end{array}$ & $\begin{array}{c}\mathrm{g}_{\mathrm{i}}: \text { Worth } \\
\text { Correction }\end{array}$ & $\begin{array}{c}\text { Minimal Worth } \\
\text { Wxfixgi }\end{array}$ \\
\hline Sm-149 & 0.935 & 0.5 & 1.02 & 0.48 \\
\hline Nd-143 & 0.540 & 0.93 & 1.0 & 0.51 \\
\hline Gd-155 & 0.425 & 0.7 & 0.96 & 0.29 \\
\hline Rh-103 & 0.423 & 0.8 & 0.84 & 0.28 \\
\hline Cs-133 & 0.222 & 0.93 & 0.88 & 0.18 \\
\hline Tc-99 & 0.171 & 0.59 & 0.93 & 0.09 \\
\hline Sm-152 & 0.150 & 0.78 & 0.99 & 0.12 \\
\hline Sm-147 & 0.137 & 0.67 & 0.97 & 0.09 \\
\hline Nd-145 & 0.104 & 0.98 & 0.99 & 0.10 \\
\hline Mo-95 & 0.077 & 0.8 & 0.81 & 0.05 \\
\hline Eu-153 & 0.074 & 0.60 & 0.81 & 0.04 \\
\hline Ag-109 & 0.040 & 0.8 & 0.96 & 0.03 \\
\hline ToTALs & 3.30 & & & 2.26 \\
\hline
\end{tabular}

Total FP Worths: $7.12 \%$

From Experimental Data: $2.26 \%$ are known 


\section{APPENDIX A: MODEL VALIDATION}

Several approximations have been made in the DRAGON model used for the CERES analysis:

1. The model is spatially limited in both radial and axial directions. In particular, it does not extend all the way to the external neutron source. All leakage is represented by an equivalent critical buckling. This approximation is justified by the experimental setup, which was intended to produce a fundamental mode. It is verified by the low sensitivity of the results to a large variation of the buckling (from critical to 0): see Table A1.

2. The fuel dimensions are not known exactly. Nevertheless, it is shown in Table A1 that the results are insensitive to a water density variation of $10 \%$.

3. The uranium content of the test sample is relatively poorly described in the literature. Nevertheless, it is shown in Table A1 that the results are insensitive to a fuel density variation of $10 \%$ in the test sample.

Table A1 provides the relative difference between the sample worth calculated with B-VI and JEF-2 for the four fission products with the highest discrepancy: Cs-133, Tc-99, Eu-153, and Sm-149 for four cases:

- reference case

- $\quad$ buckling set to 0

- water density reduced by $10 \%$

- fuel density in the sample reduced by $10 \%$

Table A1. Sensitivity of $\frac{\text { Worth (B-VI)-Worth (JEF) }}{\text { Worth (JEF) }} * 100$ to Various Modeling Issues

\begin{tabular}{|c|c|c|c|c|}
\hline Isotope & Reference & $\mathrm{B}=0$ & Water-10\% & Fuel-10\% \\
\hline Cs-133 & 5.70 & 5.75 & 5.32 & 5.62 \\
\hline Tc-99 & 4.21 & 4.16 & 4.37 & 4.16 \\
\hline Eu-153 & -5.23 & -5.02 & 5.32 & 5.24 \\
\hline Sm-149 & 2.30 & 2.54 & 2.17 & 2.29 \\
\hline
\end{tabular}


Distribution:

C. H. Adams

H. S. Khalil

S. W. Wegerich

R. Agrawal

R. M. Lell

J. W. Ahrens

H. Ley

J. C. Beitel

J. J. R. Liaw

R. A. Wigeland

H. E. Bliss

R. N. Blomquist

R. D. McKnight

K. J. Miles

A. M. Yacout

N. Zavaljevski

RA Division (15)

L. L. Briggs

A. Mohamed

J. E. Cahalan

E. E. Morris

R. J. Cornella

Q. NguyenLe

K. L. Derstine

R. N. Nietert

G. Palmiotti

F. E. Dunn

P. A. Pizzica

TIS Files, 203

T. H. Fanning

E. E. Feldman

J. Reifman

Y. I. Chang, OTD-ERD, 208

E. K. Fujita

J. Roglans

J. J. Laidler, CMT, 205

T. Sofu

E. M. Gelbard

C. G. Stenberg

J. A. Stillman

D. J. Hill, RE, 208

T. A. Taiwo

D. R. Pedersen, RE, 208

D. P. Weber, RE, 208

K. N. Grimm

K. C. Gross

J. P. Herzog

A. M. Tentner

S. K. Bhattacharyya, TD, 360

P. J. Finck, TD, 360

T. J. Yule, TD, 360

R. N. Hill

R. N. Hwang

B. J. Toppel

J. E. Matos, TD, 362

R. B. Vilim

L. C. Walters, ED ANL-W, 752

Kalimullah

D. C. Wade

D. L. Porter, ED ANL-W, 752

H. P. Planchon, ED ANL-W, 752

\section{External Distribution for the ANL-FRA Report Series}

Office of International Nuclear Safety, NE-30, FORS

Office of Engineering and Technology Development, NE-50 GTN

Reactor Analysis Division Review Committee:

R. O. Anderson, Northern States Power Company, Minneapolis

A. F. Henry, Massachusetts Institute of Technology, Cambridge

W. G. Kastenberg, University of California, Berkeley

J. C. Lee, University of Michigan, Ann Arbor

V. H. Ransom, Purdue University, West Lafayette

S. P. Schultz, Yankee Atomic Electric Company, Bolton

E. Lewis, Northwestern University, Evanston, IL (5)

W. F. Miller, Jr., Los Alamos National Laboratory, Los Alamos, NM

R. Little, Los Alamos National Laboratory, Los Alamos, NM

J. Felty, DOE-DP

W. Lake, DOE-RW

D. Cabrilla, DOE-EM

M. Westfall, Oak Ridge National Laboratory, Oak Ridge, TN

D. Lancaster, TRW

T. Doering, FRAMATOME-COGEMA

D. Carlson, NRC

C. Withee, NRC

C. Nilsen, NRC

ANL-East Library

ANL-West Library

DOE-OSTI (2) - Office of Scientific and Technical Information
(Suokko)

(Lange) 